\title{
El perfil profesional y político de las mujeres electas como alcaldesas en los municipios de Centroamérica entre 2017 y 2020
}

\section{The professional and political profile of women elected as mayors in the municipalities of Central America from 2017 to 2020}

\author{
Rafael Cedillo Delgado* \\ doi.org/10.29043/liminar.v20i1.893
}

Resumen: En este artículo se explica quiénes son y cuál es el perfil profesional y político que tienen las alcaldesas en Centroamérica. Con base en información bibliohemerográfica, y la utilización de tres tipos de perfiles, se encontró que las alcaldesas electas se caracterizan por: desarrollar actividades profesionales, ocupar cargos de dirección partidista y burocrática, contar con vínculos familiares de poder y ser proclives a la reelección; las alcaldesas con poca experiencia tienen como rasgos distintivos haber desarrollado labor partidista y haber ocupado cargos en consejos municipales y gobiernos locales, mientras que las alcaldesas ciudadanas se identifican por su prestigio social y por haber llevado a cabo trabajo comunitario y gestión de servicios.

Palabras clave: perfil político, mujeres, gobierno municipal, cargos políticos, elecciones municipales.

Abstract: This article explains who the women mayors in Central America are and describes their professional and political profiles. Based on a review of the literature and relevant periodicals, in addition to the use of three types of profiles, we found that experienced women mayors are characterized by carrying out professional activities, holding positions within political parties and governmental leadership, having family ties to influential actors, and being prone to reelection. Inexperienced women mayors have undertaken work within political parties and have occupied positions in municipal councils and local government. Women mayors are known for possessing social prestige and undertaking community work and management of services.

Key words: political profile, women, municipal government, political positions, local elections.

Recibido: 19 de agosto de 2020 Aceptación: 14 de junio de 2021 Publicación: 4 de noviembre de 2021
* Universidad Autónoma del Estado de México, campus Amecameca, México rafacd2000@yahoo.com.mx (iD) 0000-0001-6307-7062 


\title{
Introducción
}

\begin{abstract}
$\mathrm{C}$ entroamérica es una región integrada por siete países - Belice, Guatemala, El Salvador, Honduras, Panamá, Nicaragua y Costa Rica- que comparten un proceso histórico que los une, problemas en común y desafíos por cumplir. Dos son las asignaturas apremiantes que tienen como naciones independientes: por un lado, establecer regímenes democráticos y, por el otro, superar la situación de atraso y pobreza que prima en la región. En cuanto al tema político, cabe señalar que Centroamérica encara el siglo XXI con el peso de una larga etapa de inestabilidad política, de reajuste constitucional y de recomposición de la cohesión social. Como señala Carol González-Villarreal:
\end{abstract}

Con excepción de Costa Rica, los países de la región, incluido Panamá, fueron sacudidos a lo largo de la década de los ochenta hasta fines de la década de los noventa, por un conflicto político-militar, que afectó profundamente su tejido social. Entrado el siglo XXI hasta la actual época, la puesta en marcha de Acuerdos de Paz, el proceso de retorno a la democracia formal en los países afectados por el enfrentamiento armado y las tendencias de descentralización de las decisiones de gobierno en Costa Rica, marcaron el comportamiento político y social de las naciones centroamericanas (GonzálezVillarreal, 2017, p. 17).

Con excepción de Belice, que es una monarquía constitucional parlamentaria, los países de la región buscan fortalecer sus sistemas políticos con un ejecutivo fuerte, pero con equilibrio de poderes y sin el lastre del autoritarismo. En Centroamérica hay países con regímenes políticos formalmente democráticos, donde se realizan elecciones y se renuevan los cargos públicos de manera periódica. Hablamos de regímenes presidenciales cuyo mando recae en los poderes Ejecutivo y Legislativo nacionales, pero que también contemplan la descentralización y poderes en las diversas regiones y municipios; esta última instancia administrativa es la más pequeña, pero la más cercana a las necesidades de la sociedad, de ahí la importancia del gobierno municipal. Como señala Carol González-Villarreal:

En todos los países de la región, la autonomía municipal está presente y regulada en la normativa, donde el municipio se define como la división político administrativa, siendo una unidad básica de administración territorial. Las diferentes legislaciones, determinan aspectos básicos relacionados al ámbito político administrativo, al de recursos económicos, al de competencias y servicios, y relativos al desarrollo. Entre los puntos en común se encuentran: La autonomía municipal, la elección de alcalde, síndicos y concejales por medio de sufragio universal y la posibilidad de contar con ingresos por concepto contributivo (ingresos fiscales, impositivos tributarios, rentas tributarias, etc.); es decir, la potestad de generar sus propios recursos e invertirlos en el municipio (González-Villarreal, 2017, p. 50).

Estudios recientes sobre Centroamérica tratan de explicar la intrincada dificultad para establecer sociedades con instituciones políticas fuertes y estables en países como Guatemala, El Salvador y Nicaragua, mientras otros intentan exponer algunas debilidades de la democracia en países como Costa Rica (Álvarez et al., 2019). Otros se ocupan de la cultura política y de los sistemas de partidos 
en países como Honduras (Castellanos y Romero, 2019), Panamá (Valdés, 2007) o Belice (Hoffman, 2009). Sobre la vertiente relativa a la participación política de la mujer se encuentra información en estudios sobre las políticas de cuota de género en América Latina (Fernández, 2011; Freidenberg y Lajas, 2014) y en Centroamérica (Letona, 2017), y en análisis de casos de Nicaragua (Comisión Interamericana de Mujeres, 2016), Honduras (Freidenberg, 2019), Panamá (Freidenberg y Brown, 2019), Belice (Programa de las Naciones Unidas para el Desarrollo, 2012) y Costa Rica (Bolaños, 2006); en estudios resaltan los progresos por alcanzar la democracia paritaria y los innegables avances de la mujer en la representación parlamentaria, y se subraya la baja participación de mujeres en los gobiernos municipales, área de estudio poco abordada.

Las indagaciones sobre partidos políticos, elecciones y cuotas de género en Centroamérica son relevantes porque permiten conocer, con base en el análisis de las reformas electorales y prácticas partidistas, qué tanto se ha avanzado en la participación política de las mujeres como alcaldesas, e igual de importante es explicar quiénes son las mujeres que han ocupado estos cargos, no solo en cuanto a su número y porcentaje de participación, sino sobre su formación académica y política, su experiencia y la evaluación de su ejercicio gubernamental. En esa tesitura destaca el estudio de Alejandra Massolo (2007) sobre gobiernos locales en América Latina, en el que la autora analizó los efectos negativos del sistema electoral de partidos y las prácticas políticas sobre la participación de la mujer en el ámbito municipal; asimismo, delineó el perfil de las alcaldesas por rango de edad (36-43 años), estado civil (63\% casadas), escolaridad (54\% con bachillerato o licenciatura) y tipo de municipios que gobiernan (Massolo, 2007).

Para el caso de Centroamérica destacan amplios estudios sobre el perfil sociopolítico de las alcaldesas de El Salvador (Urquilla, 2016), Costa Rica (Obando, 2016) y Panamá (Bernal, 2016), cuyos autores y autoras, con base en datos estadísticos, confirman varios de los rasgos descritos por Massolo y puntualizan la clara relación entre las mujeres aspirantes al cargo con la carrera político-partidista, los antecedentes familiares de participación política y mayor desarrollo en capacitación y formación política (2017, p. 59). En general, la información sobre alcaldesas en la región incluye el número y el porcentaje que representan, el partido político al que pertenecen y, en menor medida, su nivel de estudios; sin embargo, es difícil encontrar datos sobre su formación profesional, su trayectoria política y su experiencia en el cargo, como sí ocurre con las legisladoras o jefas de Estado. Parece que las huellas y pasos de los senderos de las mujeres como alcaldesas en Centroamérica están invisibilizados. Los diagnósticos efectuados sobre este tema indican una baja representación y una enorme brecha entre géneros en cuanto a empoderamiento. Alejandra Massolo señala lo siguiente:

Siendo el municipio la instancia de representación y gobierno más próxima a la ciudadanía, vinculada a los asuntos de la vida cotidiana, paradójicamente no ha facilitado el acceso de las mujeres a los cargos de representación municipal. Los gobiernos locales latinoamericanos carecen de pluralidad de género, puesto que son mayoritariamente encabezados por hombres. Claramente no se verifica una correlación positiva entre mayor cercanía y mayor participación de las mujeres en los cargos de representación y dirección. Por lo cual, el principio de proximidad que legitima específicamente al gobierno local, no funciona como principio que favorece la equidad de género (Massolo, 2007, p. 47). 
Promover la representación política de las mujeres, como un medio necesario para alcanzar una democracia sustantiva, eficiente, eficaz e incluyente en Centroamérica, tiene que ver con el impulso de acciones afirmativas de género y de políticas públicas en favor de la igualdad de oportunidades entre hombres y mujeres; pero también es necesario encumbrar el papel de las alcaldesas y ofrecer mayor información sobre su hoja de vida. Por ello, se considera importante analizar quiénes son las mujeres que han ocupado el principal cargo en la administración pública municipal en el contexto centroamericano, además de construir sus perfiles, lo que permitirá identificar sus características profesionales, políticas y sociales.

En este artículo se explica quiénes son y cuál es el perfil profesional y político de las alcaldesas en Centroamérica que fueron electas entre 2017 y 2020. Debido a la falta de información sistematizada sobre ellas, principalmente en los casos de El Salvador y Nicaragua, se utilizaron tres fuentes: 1) la oficial, proporcionada por los institutos electorales de cada país, en la que se ofrecen datos biográficos y de experiencia política, 2) la divulgada por los partidos políticos sobre la trayectoria social y política de sus candidatas, y 3) la publicada por periódicos, en que hacen referencia a historias personales, familiares o de escándalos públicos de las candidatas. El análisis se realizó a través del método comparativo, con el cual se examinan las diferencias y semejanzas de tres tipos de perfiles: experimentadas, con actividad previa en cargos partidistas y de gobierno; no experimentadas, militantes partidistas o con alguna participación en la burocracia municipal y ciudadanas, quienes destacan por su actividad en el ámbito social o comunitario. El fin es establecer los rasgos distintivos de las alcaldesas en Centroamérica y destacar las áreas de oportunidad para incrementar la participación de las mujeres.

El trabajo está organizado en tres apartados. En el primero se exponen las características del enfoque de paridad de género y se señalan los criterios e indicadores para establecer los perfiles de las alcaldesas, referidos al contexto social y político de Centroamérica. En el segundo se hace un análisis descriptivo de la formación profesional, la trayectoria política y la experiencia burocrática de las alcaldesas en los siete países de la región. En el tercero se presenta un análisis comparativo de los tres tipos de alcaldesas con el fin de destacar sus características y los espacios de oportunidad para incrementar la participación política de las mujeres como cabezas de los gobiernos municipales.

\section{La paridad de género y el perfil de las alcaldesas de Centroamérica}

La paridad de género, como perspectiva que propone medidas para alcanzar la igualdad de oportunidades entre hombres y mujeres, es el enfoque desde el cual se analiza la participación política de las mujeres como alcaldesas en los municipios de Centroamérica. El concepto se utiliza para analizar los diferentes factores que impiden la competencia equilibrada entre géneros en los ámbitos educativos, económicos, sociales y políticos; entre los obstáculos se destacan tres dimensiones: 1) estructurales, referidas a las desigualdades de género producidas en el mercado laboral, niveles educativos o brechas de ingreso; 2) culturales o ideológicas, referidas a las creencias sobre el rol de la mujer en la sociedad y sus efectos en la capacidad, interés y oportunidad para acceder al poder político, y 3) las políticas institucionales, vinculadas a las instituciones que rigen el comportamiento político, como las normas del sistema electoral o de partidos políticos (Ríos, 2008). Dicho contexto de limitaciones y prácticas discriminatorias hacia las mujeres ha provocado el surgimiento del enfoque de paridad de género, que en términos generales: 
busca que mujeres y hombres participen en igualdad de condiciones en todas las actividades de la sociedad, especialmente en cargos públicos. La paridad implica que ningún género tenga más de $40 \%$ de los cargos o, en su versión más radical, establece una distribución de $50 \%$ a $50 \%$. Asimismo, constituye una fórmula que busca superar la idea de una "ciudadanía neutra" a través de la proporcionalidad equitativa de mujeres y hombres en todos los órganos de decisión y representación pública (Medina, 2010, pp. 27-28).

El principio de paridad de género engloba, entonces, todas las políticas, medidas legales y acciones que tienen el propósito de alcanzar la igualdad sustantiva entre hombres y mujeres. En el ámbito político se plantea garantizar la postulación y el acceso de las mujeres a todos los cargos de gobierno y parlamentarios, ampliar los espacios de participación pública y mejorar la representación en la actividad pública. El objetivo es desterrar las prácticas de discriminación de que son objeto, superar los prejuicios sociales y culturales que varones, instituciones y sociedad les imponen y eliminar las "barreras" reales e imaginarias que impiden alcanzar la igualdad sustantiva; es decir, romper el llamado techo de cristal, concepto que hace referencia a:

Las barreras invisibles o veladas que limitan e impiden a las mujeres el ascenso a niveles jerárquicos superiores dentro de organizaciones o la disposición de ingresos más igualitarios respecto a sus pares masculinos: un juego de palabras para ilustrar cómo pese a estar involucradas en los espacios productivos y siendo actoras importantes dentro de la actividad económica, existirían elementos invisibles - vinculados a la construcción de género- que impiden que puedan tener una participación o reconocimiento equitativo y similar al de sus pares masculinos (Instituto Holandés para la Democracia Multipartidaria, 2019, p. 7).

En el ámbito político las cuotas de género se han constituido como el principal mecanismo para que las mujeres ganen espacios de inclusión en el sistema político, con lo cual se ha logrado mejorar ligeramente su representación política en las distintas esferas de gobierno. Sin embargo, se debe subrayar que el avance de empoderamiento de las mujeres será limitado si no ejercitan la participación política, concepto este en el cual se engloban todas las acciones y conductas que apuntan a influir en las decisiones públicas y que varían en grado de intervención. Comprende acciones como: votar, asistir a un mitin o asamblea, estar afiliado a un partido político, influir sobre otras personas sobre preferencia política, ser postulado como candidato o candidata a un cargo de elección o tener un cargo público o de partido (Pasquino, 2004).

En el ámbito de la participación política de las mujeres como alcaldesas en Centroamérica es importante considerar el impacto de las cuotas de género y el análisis de las causas que limitan su inclusión como candidatas, pero es igual de importante revisar si su perfil profesional y político tiene relación con su postulación al cargo, es decir, explicar si su hoja de vida, su trayectoria social y política y sus características personales influyen en la obtención del cargo. El perfil de las candidatas comprende; datos personales, características sociales y culturales, condiciones de vida, origen político, desempeño laboral, profesión, trayectoria social o comunitaria y redes sociales (Massolo, 2007); dichos rasgos son relevantes porque ayudan a entender qué elementos personales y profesionales de las mujeres evalúan los partidos políticos para postularlas como candidatas, y qué aspectos toma en cuenta la ciudadanía para otorgarles o negarles su voto en su camino para alcanzar el cargo. 
Cabe señalar que el alcalde o alcaldesa es quien dirige el aparato burocrático administrativo de la comunidad y encabeza el Consejo Municipal, por ello es la figura política de mayor jerarquía en los municipios y representa el icono político más importante en el ámbito local. Administrativamente, el o la titular de la alcaldía es responsable de la dirección, planeación, organización y materialización de las decisiones que satisfacen las demandas de la población gobernada; políticamente, es líder, coordinador(a), gestor(a) y representante de los asuntos municipales de cara a alcanzar el mayor bienestar para la comunidad. Electoralmente es el cargo público que más atrae a la ciudadanía por ser la autoridad pública más cercana y porque consideran que es quien se encargará de atender y satisfacer sus necesidades inmediatas, como servicios públicos, educación, empleo, salud y seguridad.

Los gobiernos municipales en Centroamérica recaen en un Consejo que está integrado por un alcalde o alcaldesa, uno(a) o dos vicealcaldes(as) o síndicos(as), y un número variable de regidores(as) o concejales(as). Las decisiones sobre el rumbo que sigue la administración pública municipal son tomadas en forma colegiada por el Consejo Municipal, el cual está encabezado y dirigido por un alcalde o alcaldesa, quien es electo(a) por mayoría relativa para ejercer durante un periodo establecido y en muchas ocasiones con posibilidad de reelección. Las alcaldías se eligen, al mismo tiempo que los miembros del Consejo Municipal, mediante el sistema de "planillas" y se renuevan, en su totalidad, el mismo año en que ocurre la elección. En Belice, Guatemala, El Salvador y Nicaragua, las elecciones son cada tres años, en Honduras y Costa Rica cada cuatro y en Panamá cada cinco. La cantidad de municipios (distritos o cantones) son: nueve en Belice, 81 en Panamá, 82 en Costa Rica, 153 en Nicaragua, 262 en El Salvador, 298 en Honduras y 340 en Guatemala.

Las elecciones municipales recientes en las que se eligió a los(as) alcaldes(sas) y miembros de los consejos municipales, se realizaron en Honduras y Nicaragua en 2017, en Belice y El Salvador en 2018, en Guatemala y Panamá en 2019 y en Costa Rica en 2020. Los países que cuentan con sistema de cuotas de género son: Nicaragua, Costa Rica, Panamá y Honduras, del 50 \% y El Salvador de un $30 \%$, mientras en Belice y Guatemala no existe tal sistema (Comisión Interamericana de Mujeres, 2016). El dato es relevador porque parece haber una estrecha relación entre representación política femenina e implementación de cuotas de género; en Nicaragua resultaron electas 65 mujeres (42.5\%), doce en Panamá (14.8 \%), nueve en Costa Rica (11 \%), 28 en El Salvador (10.7 \%), 23 en Honduras (7.7 \%), once en Guatemala (3.2 \%) y ninguna en Belice. Los resultados electorales recientes revelan que no se ha logrado incrementar la representación política de las mujeres debido, entre otros factores, a la ausencia o baja efectividad de la aplicación de las cuotas de género, ya que las prácticas de simulación y los resquicios normativos en las leyes electorales y de partidos políticos limitan la inclusión de las mujeres como candidatas a alcaldías y, por tanto, determinan su baja participación política (Cedillo, 2021).

Se ha confirmado que, en Centroamérica, para los cargos de este tipo la representación de la mujer se ubica en el umbral del 12 y que, salvo en el caso de Nicaragua, los países de la región no logran rebasar lo que el Observatorio de Igualdad de Género de América Latina y el Caribe llama la "barrera" para municipios encabezados por una mujer en América Latina, que es del 30 \% (Comisión Económica para América Latina y el Caribe, 2013). Los partidos políticos de la región aún tienden a privilegiar candidatos masculinos como cabeza de planilla, cumplen las cuotas electorales colocando a mujeres en segundo lugar en las planillas municipales o las incluyen como suplentes, por lo que "el número de alcaldesas progresa lentamente, o se estanca, en alrededor de 10 \%-15 \%” (Romero, 2016, p. 14). En 
dicho contexto se han hecho evidentes distintas formas de violencia política en contra de las mujeres, violentando sus derechos para ser postuladas como candidatas y limitando su representación política en los gobiernos municipales (Krook, 2017; Torres, 2018).

Sin embargo, más allá del número de alcaldesas en Centroamérica, resulta de interés definir su perfil sin estereotipos valorativos de superioridad o inferioridad, sino con base en criterios e indicadores que hagan referencia a sus cualidades profesionales, políticas y personales para ocupar el cargo. La propuesta para definir los perfiles de las alcaldesas tiene como base un estudio elaborado para el caso mexicano ${ }^{1}$ por ONU Mujeres (2018), complementada con indicadores característicos del contexto centroamericano, región que emerge de una etapa de guerras civiles y experiencias autoritarias, en donde destaca el rol desarrollado por las mujeres en los espacios público y privado (Herrera, 2010), como el salto de la participación social y comunitaria a ser potenciales candidatas (Tello, 2009), y aspectos como la experiencia política, la reelección, los vínculos familiares de poder y el prestigio académico y profesional para ocupar la alcaldía (Massolo, 2007; Tello, 2009).

Con base en los indicadores planteados en los estudios mencionados, además de las características destacadas de las mujeres en el contexto social y político de Centroamérica, se proponen tres tipos de perfiles para alcaldesas en los que se destaca la formación académica y profesional, la experiencia burocrática, política o social de su trayectoria, las redes de poder y la reelección en el cargo. Los perfiles son: 1) alcaldesas experimentadas, 2) alcaldesas con poca experiencia y 3) alcaldesas ciudadanas.

1) Alcaldesas experimentadas. Son mujeres que cuentan con estudios de licenciatura o posgrado, por lo que realizan actividades profesionales como abogadas, contadoras, médicas o maestras principalmente, aunque también hay ingenieras, arquitectas, economistas y politólogas. Han ocupado previamente un cargo de elección popular en el ámbito local (alcaldesa, vicealcaldesa, sindica, regidora o concejal), estatal o federal (diputadas o senadoras), y cuentan con experiencia partidista o en la administración pública municipal o estatal. Suelen tener mayor espacio de oportunidad para la reelección por la experiencia acumulada, el desempeño en el cargo de alcaldesa y por tener vínculos familiares cercanos con algún líder político local.

2) Alcaldesas con poca experiencia. Son mujeres con estudios técnicos, de nivel de bachillerato, secundaria o básico. Han participado como candidatas suplentes en cargos de elección, principalmente en el cabildo municipal (concejalas), han trabajado en la burocracia municipal o han realizado labor permanente en la estructura partidista. Se ocupan en actividades económicas fuera de la esfera política (microempresarias, subgerentes, comerciantes o empleadas). La oportunidad para reelegirse es reducida, y para lograrlo requieren ganarse, con su desempeño, el respaldo ciudadano, además de contar con el apoyo de un partido político.

3) Alcaldesas ciudadanas. Son mujeres que pueden o no tener estudios profesionales porque el nivel de estudios no las determina, sino el rol que desempeñan en la comunidad. Tienen poca o nula experiencia en cargos de elección, en la burocracia administrativa y en los partidos políticos. Suelen ser dirigentes

\footnotetext{
${ }^{1}$ En el caso mexicano se proponen cinco perfiles de candidatas a presidentas municipales: 1) experimentada, 2) en busca de la reelección, 3) con lazos familiares con algún líder político, 4) con poca experiencia política y 5) testimonial (ONU Mujeres, 2018, pp. 39-44). En este texto se destacan solo tres perfiles, pues en México, a diferencia de los países de Centroamérica, la reelección municipal es relativamente reciente, de 2014, y el análisis de datos se realizó con candidatas y no con mujeres que ya ocupaban el cargo de alcaldesa.
} 
sociales o liderar alguna agrupación comunitaria o gremio de trabajadores. Son invitadas por los partidos políticos para contender para la alcaldía por su trabajo en la comunidad y su buena reputación, más que por su experiencia. Obtienen el cargo por su arraigo social y, por lo mismo, la posibilidad de reelección depende de su desempeño en el cargo.

Entre los perfiles de alcaldesas se incluye este último, el de "ciudadana", por la particularidad del contexto centroamericano, debido a que en la etapa de posguerra civil en El Salvador, Guatemala y Nicaragua las mujeres destacan más por su labor social y comunitaria que por ser profesionistas; de igual forma, se utiliza la reelección como indicador clave, porque en los países de la región es una práctica frecuente. Con estos perfiles de alcaldesas no se busca establecer las condiciones que deben reunir las mujeres que aspiran al cargo, sino solo destacar las cualidades personales, profesionales y políticas que revelan su formación y trayectoria, de tal forma que ningún perfil es mejor que otro, sino que cada alcaldesa posee rasgos distintivos de empoderamiento.

\section{Análisis descriptivo del perfil de las alcaldesas de Centroamérica}

Con el objetivo de superar una visión meramente cuantitativa de la representación política de las mujeres en Centroamérica e ir más allá del número y su porcentaje, a continuación se presenta un análisis descriptivo del perfil de las alcaldesas de la región. Los perfiles especificados se refieren a la cualidad de las mujeres en el cargo, electas, salvo en el caso de Belice, entre los años 2017 y 2020; el análisis permite ubicar a las alcaldesas en cada país como experimentadas, poco experimentadas o ciudadanas, en virtud de su actividad profesional, su recorrido burocrático y su experiencia municipal, además de destacar rasgos particulares como la reelección, los vínculos familiares de poder y la trascendencia política en el ámbito local o nacional. La presentación se efectuará con base en el porcentaje de representación femenina: primero en el caso de Belice, luego Guatemala, Honduras, El Salvador, Costa Rica y Panamá, y al final Nicaragua, que presenta el mayor número de casos.

\section{Belice}

En las elecciones municipales en Belice de 2018 ninguna mujer resultó electa en las alcaldías; sin embargo, este país sí ha contado con participación femenina, incluso en el periodo 2006-2012 las mujeres alcanzaron el $22.2 \%$ de representación política para alcaldías (Palacio, 2009). A fin de establecer el perfil de las alcaldesas se revisaron los casos de: Sylvia Sarita Flores Ávila, Elsa Paz y Zenaida Victoria Moya. El análisis de trayectorias indica que Silvia Flores Ávila es experimentada, pues, además de ser profesionista, con estudios en Economía y Ciencias Políticas, ganó el cargo de alcaldesa en dos ocasiones, fue diputada y senadora y ocupó la cartera de ministra de Desarrollo Humano y Mujeres (Caribbean Election, 2020; González, 2019). Zenaida Victoria Maya, administradora de empresas, también es experimentada porque fue dos veces alcaldesa y, aunque desarrolló su trayectoria en organizaciones sindicales y cooperativas, laboró en el Ministerio de Desarrollo Económico (Palacio, 2009). Elsa Paz, por su parte, es experimentada por haber sido alcaldesa en tres ocasiones, pero también tiene perfil ciudadano ya que realizó trabajo social y comunitario, además de desempeñarse en cargos de la burocracia local (ver Tabla 1). 
Tabla 1. Perfil de alcaldesas "históricas" en Belice

\begin{tabular}{|c|c|c|c|c|c|c|c|}
\hline \multirow{2}{*}{ Nombre } & \multirow{2}{*}{ Estudios } & \multicolumn{3}{|c|}{ Experiencia* } & \multirow{2}{*}{\multicolumn{2}{|c|}{ (R)Elección }} & \multirow{2}{*}{$\begin{array}{l}\text { Perfil de } \\
\text { alcaldesa }\end{array}$} \\
\hline & & Ep & $\mathrm{Eb}$ & Esc & & & \\
\hline $\begin{array}{l}\text { Sylvia Sarita Flores Ávila (1988 a } \\
\text { 1993) }\end{array}$ & $\begin{array}{l}\text { Lic. en Economía } \\
\text { y Ciencia Política }\end{array}$ & $x$ & $x$ & - & Sí & 2 & Experimentada \\
\hline Elsa Paz (2003-2012) & Sin profesión & $x$ & - & $x$ & Sí & 3 & $\begin{array}{l}\text { Experimentada/ } \\
\text { ciudadana }\end{array}$ \\
\hline Zenaida Victoria Moya (2006-2009) & $\begin{array}{l}\text { Administración de } \\
\text { Empresas }\end{array}$ & $x$ & $x$ & $x$ & Sí & 2 & Experimentada \\
\hline
\end{tabular}

* (Ep). Experiencia política; (Eb) Experiencia burocrática y (Esc) Experiencia social o comunitaria. Fuente: elaboración propia con información de Toussain (1990), Palacio (2009), Hoffmann (2009), González (2019) y Caribbean Election (2020).

\section{Guatemala}

La representación política de las mujeres en las alcaldías de Guatemala, en 2019, fue de once de 340 municipios (el $3.2 \%$ ); su filiación partidista se distribuyó así: cuatro de Unidad Nacional de la Esperanza (UNE), dos de Unión Cambio Nacional (UCN), dos de Podemos y una de los partidos Todos, Valor y Vamos (Quinteja, 2020; Sánchez, 2019). En este país, el número de alcaldesas poco experimentadas es mayor, a pesar de que siete de las once alcaldesas cuentan con estudios de licenciatura, y ejercen profesiones en los campos de educación, contaduría, trabajo social y medicina; el factor que determina esto es el bajo número de mujeres que repiten en el cargo, solo cuatro. Lo que caracteriza a las alcaldesas es haber ocupado con anterioridad algún cargo burocrático o partidista (Ramos, 2019): Alicia Méndez en la Asociación Brazos Amorosos; Dora Aldina Pérez, coordinadora del Fondo Nacional para la Paz (FONAPAZ); Floridalma Morales, promotora de participación ciudadana; Mayra Elizabeth Palencia, candidata a la alcaldía en 2015, y Mirna Vargas, concejala propietaria y candidata, perdedora, a la alcaldía de Estanzuela (ver Tabla 2).

Tabla 2. Perfil de alcaldesas de Guatemala electas en 2019

\begin{tabular}{|c|c|c|c|c|c|c|c|}
\hline \multirow{2}{*}{ Nombre } & \multirow{2}{*}{ Profesión } & \multicolumn{3}{|c|}{ Experiencia } & \multirow{2}{*}{\multicolumn{2}{|c|}{$\begin{array}{c}\text { (R) } \\
\text { Elección }\end{array}$}} & \multirow{2}{*}{$\begin{array}{l}\text { Perfil de } \\
\text { alcaldesa }\end{array}$} \\
\hline & & Ep & Eb & Esc & & & \\
\hline Brenda Elizabeth del Cid Medrano & Perito Contador & $x$ & $x$ & $x$ & Sí & 2 & Experimentada \\
\hline Alicia Méndez González & Sin profesión & - & $x$ & $x$ & No & 1 & Poca exp. \\
\hline Dora Aldina Pérez Martínez & Lic. en Educación & - & $x$ & $x$ & No & 1 & Poca exp. \\
\hline Aura Marina Orantes Gaitán & Trabajo Social & - & - & $x$ & No & 1 & Ciudadana \\
\hline Floridalma Morales Contreras $\mathrm{Q}$. & Perito Contador & - & - & $x$ & No & 1 & Poca exp. \\
\hline
\end{tabular}




\begin{tabular}{|c|c|c|c|c|c|c|c|}
\hline Blanca Estela Mendoza Méndez & $\begin{array}{l}\text { Lic. en Ciencias y } \\
\text { Letras. }\end{array}$ & $x$ & $x$ & - & Sí & 2 & Experimentada \\
\hline Olga Barrios Barrios & Sin profesión & $x$ & $x$ & - & Sí & 4 & Experimentada \\
\hline Edilma ElizABEth NAVARIJO dE LEÓN & Lic. en Pedagogía & $x$ & $x$ & - & Sí & 5 & Experimentada \\
\hline $\begin{array}{l}\text { Irma Elizabeth Ávila Alvarado } \\
\text { Molina }\end{array}$ & Sin profesión & $x$ & 一 & $x$ & No & 1 & Ciudadana \\
\hline $\begin{array}{l}\text { Mayra Elizabeth Altán Palencia de } \\
\text { Palacios }\end{array}$ & Sin profesión & $x$ & 一 & - & No & 1 & Poca exp. \\
\hline Mirna Yohaira Vargas Trujillo & Médica cirujana & - & $x$ & - & No & 1 & Poca exp. \\
\hline
\end{tabular}

* (Ep). Experiencia política; (Eb) Experiencia burocrática y (Esc) Experiencia social o comunitaria. Fuente: elaboración propia con información de Sánchez (2019), González (2019), Ramos (2019) y Quinteja (2020).

Cuatro de las alcaldesas electas en Guatemala cuentan con alguna experiencia política o administrativa, tienen cierto arraigo con su comunidad y han sido refrendadas en las urnas por más de una ocasión; dos han sido reelectas por un periodo consecutivo, una ganó en cuatro ocasiones (Olga Barrios) y otra en cinco (Edilma Navarijo). Un dato sobresaliente es la pertenencia a una familia de poder: Alicia Méndez es hija del expresidente Julio César Méndez (1966-1970) y Edilma Navarijo tiene un hijo alcalde y una hija diputada. Por otro lado, solo dos alcaldesas electas son "ciudadanas"; ambas ya habían sido candidatas en 2015, reconocidas principalmente por su trabajo con la comunidad: Aura Marina Orantes destaca por su labor social y religiosa, mientras que Irma Elizabeth Ávila realiza labor en la comunidad como empresaria y emprendedora.

\section{El Salvador}

En las elecciones de 2018 en El Salvador fueron electas 28 mujeres, el 10.7 \% del total, de las cuales 20 participan en los tres principales partidos políticos: quince en Arena, cinco en GANA y cinco en el Frente Farabundo Martí para la Liberación Nacional (FMLN). En cuanto al nivel de estudios, 20 de ellas cuentan con estudios profesionales (el $71.4 \%$ ), una tiene posgrado (Victoria Hernández) y otra es pasante en Ciencias Sociales; son abogadas, médicas, maestras y egresadas de carreras administrativas (contaduría, mercadeo y relaciones públicas). No puede establecerse una clara asociación entre nivel de estudios y experiencia político-administrativa en el cargo, pues varias de las profesionistas no tienen trayectoria pública, e incluso algunas solo realizan trabajo profesional o comunitario como, por ejemplo, las doctoras Loida Eunice Loza y Yanira Beatriz Guevara, o quienes se dedican a la educación, Hilda María Velásquez y Victoria Magdalena Hernández. En una situación diferente se encuentran Marvin Morena y Pedrina Rivera, que no son profesionistas pero sí tienen mucha experiencia política (ver Tabla 3). 
Tabla 3. Perfil de alcaldesas de El Salvador electas en 2018

\begin{tabular}{|c|c|c|c|c|c|c|c|}
\hline \multirow{2}{*}{ Nombre } & \multirow{2}{*}{ Profesión* } & \multicolumn{3}{|c|}{ Experiencia** $^{\star *}$} & \multirow{2}{*}{\multicolumn{2}{|c|}{ (R) elección }} & \multirow{2}{*}{$\begin{array}{l}\text { Perfil de } \\
\text { alcaldesa }\end{array}$} \\
\hline & & Ep & Eb & Esc & & & \\
\hline $\begin{array}{l}\text { Heicy Marisela Flores de } \\
\text { Sánchez }\end{array}$ & Bachillerato & $x$ & - & - & No & 1 & Poca exp. \\
\hline $\begin{array}{l}\text { Carmen Elena Calderón Sol } \\
\text { de E. }\end{array}$ & $\begin{array}{l}\text { Lic. en Laboratorio } \\
\text { Clínico }\end{array}$ & $x$ & $\mathrm{X}$ & $x$ & Sí & 1 & Experimentada \\
\hline Vilma Josefa Turcios de Barrera & $\begin{array}{l}\text { Lic. en Ciencias } \\
\text { Jurídicas }\end{array}$ & $x$ & - & - & No & 1 & Poca exp. \\
\hline Janet Rivera de Rivera & $\begin{array}{l}\text { Lic. en Ciencias } \\
\text { Jurídicas }\end{array}$ & $x$ & $x$ & - & Sí & 5 & Experimentada \\
\hline Carmen Abigaíl Girón Canales & $\begin{array}{l}\text { Ginecología y } \\
\text { Obstetricia }\end{array}$ & $x$ & $x$ & - & No & 1 & Poca exp. \\
\hline Zoila Milagro Navas Quintanilla & $\begin{array}{l}\text { Lic. en Relaciones } \\
\text { Públicas y Pub. }\end{array}$ & $x$ & $x$ & $x$ & Sí & 11 & Experimentada \\
\hline Ana Janet González Sermeño & Sin profesión & - & - & $x$ & No & 1 & Poca exp. \\
\hline $\begin{array}{l}\text { Irma Michelle M. Ninette Sol de } \\
\text { Castro }\end{array}$ & Lic. en Mercadeo & $x$ & $x$ & $x$ & Sí & 1 & Experimentada \\
\hline Loida Eunice Loza de Pérez & Medicina General & - & - & $x$ & No & 1 & Ciudadana \\
\hline Yanira Beatriz Guevara Carballo & Medicina General & - & - & $x$ & No & 1 & Ciudadana \\
\hline $\begin{array}{l}\text { Alba Yesenia Eguizábal } \\
\text { Gutiérrez }\end{array}$ & $\begin{array}{l}\text { Lic. en Admón. de } \\
\text { Emp. }\end{array}$ & $x$ & - & - & No & 1 & Poca exp. \\
\hline Flor de María Najarro Peña & $\begin{array}{l}\text { Lic. en Admón. de } \\
\text { Emp. }\end{array}$ & - & $x$ & - & No & 1 & Poca exp. \\
\hline Blanca Maribel Solano de Sosa & Sin profesión & - & - & $x$ & No & 1 & Ciudadana \\
\hline Mirna Aracely Reyes Contreras & Lic. en Derecho & - & $x$ & - & No & 1 & Poca exp. \\
\hline $\begin{array}{l}\text { Marvin Morena Martell de } \\
\text { Canales }\end{array}$ & Sin profesión & $x$ & $x$ & $x$ & Sí & 8 & Experimentada \\
\hline $\begin{array}{l}\text { Elsa Antonia Guevara de } \\
\text { Melchor }\end{array}$ & $\begin{array}{l}\text { Lic. en Ciencias de } \\
\text { Educación }\end{array}$ & - & $x$ & $x$ & Sí & 3 & Experimentada \\
\hline Angélica María Pineda de Bran & Sin profesión & $x$ & $x$ & - & No & 1 & Poca exp. \\
\hline Mercedes Lili Bello de Perdomo & Licenciada & - & $x$ & $x$ & No & 1 & Poca exp. \\
\hline Pedrina Rivera Hernández & Sin profesión & $x$ & $x$ & $X$ & Sí & 3 & Experimentada \\
\hline $\begin{array}{l}\text { Leticia de Jesús Hernández } \\
\text { Sánchez }\end{array}$ & Trabajo Social & $x$ & $x$ & $x$ & Sí & 11 & Experimentada \\
\hline $\begin{array}{l}\text { Ana Luisa Rodríguez de } \\
\text { González }\end{array}$ & $\begin{array}{l}\text { Lab. Clínico y } \\
\text { Farmacia }\end{array}$ & $x$ & $x$ & - & Sí & 5 & Experimentada \\
\hline Hilda María Velásquez Quezada & $\begin{array}{l}\text { Formación } \\
\text { Pedagógica }\end{array}$ & - & - & $X$ & No & 1 & Ciudadana \\
\hline
\end{tabular}




\begin{tabular}{|c|c|c|c|c|c|c|c|}
\hline $\begin{array}{l}\text { Gloria Argentina Barahona de } \\
\text { García }\end{array}$ & Sin profesión & - & - & 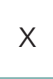 & No & 1 & Ciudadana \\
\hline Imelda Maribel Rodríguez Sorto & Licenciada & $x$ & $x$ & - & Sí & 2 & Experimentada \\
\hline $\begin{array}{l}\text { Trinidad Josefina Rivas de } \\
\text { González }\end{array}$ & $\begin{array}{l}\text { Lic. en Ciencias } \\
\text { Jurídicas }\end{array}$ & $x$ & $x$ & - & Sí & 2 & Experimentada \\
\hline Lilian Antonia Portillo de Carrillo & Sin profesión & - & - & $x$ & No & 1 & Ciudadana \\
\hline Elba Noemy López de Guillen & Pasante en CS. & $\mathrm{X}$ & X & - & No & 1 & Poca exp. \\
\hline $\begin{array}{l}\text { Victoria Magdalena Hernández } \\
\text { de López }\end{array}$ & $\begin{array}{l}\text { Lic. en Psicología, } \\
\text { Mtra. en } \\
\text { Ciencias de la } \\
\text { Comunicación }\end{array}$ & - & - & $x$ & No & 1 & Ciudadana \\
\hline
\end{tabular}

* En dos casos solo se pudo definir el nivel de estudios de licenciatura, pero no se encontró informa ción sobre la profesión.

** (Ep). Experiencia política, (Eb) Experiencia burocrática y (Esc) Experiencia social o comunitaria. Fuente: elaboración propia con información de Tribunal Supremo Electoral de El Salvador (2018), González-Oliva (2018), Instituto Salvadoreño de Desarrollo Municipal (2018) y Corporación de Municipalidades de la República de El Salvador (2020) y Instituto de Acceso a la Información Pública de El Salvador (2020).

En El Salvador hay cierto equilibrio entre alcaldesas experimentadas, poco experimentadas y ciudadanas debido, entre otros factores, al incipiente proceso de construcción democrática; se registra una mediana incidencia de reelección, y varias mujeres electas cuentan con fuertes vínculos con familias de poder. Respecto a reelección, destacan Zoila Milagro Navas y Leticia de Jesús Hernández, quienes ganaron en once ocasiones, lo que representa que permanecieron más de tres décadas como cabezas de gobierno municipal. También destacan: Marvin Morena Martell (ganaron en ocho ocasiones), Janet Rivera y Ana Luisa Rodríguez (en cinco ocasiones), Elsa Antonia Guevara y Pedrina Rivera (en tres), e Imelda Maribel Rodríguez y Trinidad Josefina Rivas (en dos). En cuanto a vínculos políticos, que confirman la idea de que los vínculos familiares de poder son causa de oportunidad política, sobresale Carmen Elena Calderón, hermana del expresidente Armando Calderón Sol, y Blanca Maribel Solana de Sosa, emergente luego del asesinato de su esposo, otrora candidato en Salcoatitán.

\section{Honduras}

En las elecciones de 2017 en Honduras fueron electas 23 mujeres, que representan el $7.7 \%$ del total. El mayor número de alcaldesas son del Partido Nacional (PN), seguido del Partido Liberal (PL) y del Partido Libertad y Refundación (LIBRE). El perfil de alcaldesas que sobresale es el de las experimentadas, un $65 \%$, determinado por el alto índice de profesionistas, por la práctica de reelección y porque registran amplia experiencia político-administrativa; doce cuentan con estudios mínimos de licenciatura - destacan las abogadas, administradoras, contadoras y profesoras-, aunque también hay una ingeniera y una arquitecta; quince de ellas ya habían ocupado el cargo en dos o tres ocasiones. Por otro lado, hay un importante número de alcaldesas ciudadanas, quienes contaban con una trayectoria más social que política y solo habían realizado actividad partidista en forma esporádica o habían participado en el Consejo Municipal, como Juana Aracely Pavón, que había sido regidora municipal en Potrerillos. Las 
alcaldesas con poca experiencia solo son tres, quienes fueron postuladas por sus nexos partidistas o por haber ocupado un cargo en el Consejo Municipal (ver Tabla 4).

Tabla 4. Perfil de alcaldesas de Honduras electas en 2017

\begin{tabular}{|c|c|c|c|c|c|c|c|}
\hline \multirow{2}{*}{ Nombre } & \multirow{2}{*}{ Estudios* } & \multicolumn{3}{|c|}{ Experiencia** $^{\star *}$} & \multirow{2}{*}{\multicolumn{2}{|c|}{$\begin{array}{c}\text { (R) } \\
\text { elección }\end{array}$}} & \multirow{2}{*}{$\begin{array}{l}\text { Perfil de } \\
\text { alcaldesa }\end{array}$} \\
\hline & & Ep & $\mathrm{Eb}$ & Esc & & & \\
\hline Tona Audonifia Pineda Castellanos & Contadora pública & $x$ & $\mathrm{X}$ & - & Sí & 3 & Experimentada \\
\hline Elcy Amanda Jiménez Tróchez & Profesora normalista & $x$ & $x$ & $x$ & Sí & 2 & Experimentada \\
\hline Carmen Alicia Paz Rodríguez & $\begin{array}{l}\text { Profesora educación } \\
\text { básica }\end{array}$ & - & $x$ & $x$ & Sí & 3 & Experimentada \\
\hline Mirian Lizet López Gáleas & Sin profesión & $x$ & - & - & No & 1 & Poca exp. \\
\hline Teodolinda Anderson Mejía & Sin profesión & $x$ & $x$ & - & Sí & 3 & Experimentada \\
\hline Fátima Idalma Juárez Padilla & Lic. en Derecho & - & $x$ & $x$ & No & 1 & Ciudadana \\
\hline Teresa Sarmiento Caballero & Sin profesión & $x$ & $x$ & $x$ & Sí & 2 & Experimentada \\
\hline Sonia Yaneth Argueta Rivera & $\begin{array}{l}\text { Lic. en } \\
\text { Mercadotecnia }\end{array}$ & - & - & $x$ & No & 1 & Ciudadana \\
\hline Brenda Marilyn Leiva Chinchilla & Sin profesión & $x$ & $x$ & $x$ & Sí & 3 & Experimentada \\
\hline Carmen Idalmi Campos Pérez & Sin profesión & - & - & $x$ & No & 1 & Poca exp. \\
\hline Esperanza López Cartagena & Lic. en Enfermería & $x$ & $x$ & $x$ & Sí & 2 & Experimentada \\
\hline Bernardina Enríquez Márquez & Sin profesión & $x$ & $x$ & - & Sí & 3 & Experimentada \\
\hline Maribel Isabel González Figueroa & Sin profesión & $x$ & $x$ & - & Sí & 2 & Experimentada \\
\hline Diana Patricia Urbina Soto & Arquitecta & $x$ & $x$ & $x$ & Sí & 2 & Experimentada \\
\hline Dunia Patricia Martínez Osorio & $\begin{array}{l}\text { Lic. en Admón. } \\
\text { Industrial }\end{array}$ & - & $x$ & $x$ & Sí & 2 & Experimentada \\
\hline Gina Yabilet Bonilla Robles & Sin profesión & - & - & $x$ & No & 1 & Ciudadana \\
\hline Vilma Yamileth Ordóñez Corrales & Sin profesión & - & $x$ & $x$ & Sí & 2 & Experimentada \\
\hline Celfida Amada Bustillo Cerna & Sin profesión & $x$ & $x$ & - & Sí & 3 & Experimentada \\
\hline Ligia Isabel Laínez Bermúdez & Lic. en Admón. & - & $x$ & $x$ & Sí & 2 & Experimentada \\
\hline Juana Aracely Pavón Alcerro & Lic. en Derecho & - & $x$ & $x$ & No & 1 & Poca exp. \\
\hline Tania Belinda Fuentes Villeda & Sin profesión & - & - & $x$ & No & 1 & Ciudadana \\
\hline Teonela Paisano Wood & $\begin{array}{l}\text { Lic. en Educación } \\
\text { Técnica para el } \\
\text { Hogar }\end{array}$ & $x$ & $x$ & - & Sí & 2 & Experimentada \\
\hline Xiomara Ulloa Flores & Ingeniera & $x$ & $x$ & - & No & 1 & Ciudadana \\
\hline
\end{tabular}

* (Ep). Experiencia política, (Eb) Experiencia burocrática y (Esc) Experiencia social o comunitaria. Fuente: elaboración propia con información de Funes (2014), Tribunal Superior de Elecciones (2018), Sosa (2018) y Freidenberg (2019). 
Un aspecto por destacar es que cuatro alcaldesas de Honduras cuentan con vínculos de parentesco con algún líder político, rasgo que genera mayor espacio de oportunidad para ser candidatas, ya que son atractivas electoralmente. Se puede mencionar a Miriam Lizet López, hermana de la alcaldesa saliente Iveth Geraldine López Gáleas; a Carmen Idalmi Campos, quien era esposa del alcalde asesinado, en 2015, Santiago Mejía Díaz; a Diana Patricia Urbina Soto, hermana de Arnaldo Urbina, exalcalde de Yoro (20102013), y a Gina Yabilet Bonilla Robles, hermana del alcalde fallecido en 2017, Edam Antonio Bonilla Robles. Se puede afirmar que en Honduras el peso del parentesco político es un factor que influye en la postulación de las candidaturas partidistas.

En Honduras, como en Guatemala y El Salvador, algunas mujeres han sido postuladas o sustituidas como candidatas debido al vínculo con algún familiar varón. Al respecto, valga recordar la práctica de sustitución de mujeres candidatas por algún familiar varón (esposo, hermano o hijo) en México, conocida como "las Juanitas", medio utilizado para burlar la aplicación de cuotas de género (Cedillo, 2019). El término se aplica para hacer referencia a la práctica de postulación de mujeres, que después renuncian a su cargo para ceder el lugar a los varones, por acuerdo y como respuesta a los intereses de los dirigentes de los partidos políticos (Rodríguez, Arriaga y Ángeles, 2013). La experiencia de participación de las mujeres como candidatas en Centroamérica, como se observa, también registra casos de conveniencia política por parentesco.

\section{Costa Rica}

En Costa Rica, país que ha impulsado decididamente la participación política de las mujeres, en las elecciones de 2020 solo fueron electas nueve alcaldesas en los 82 municipios (el $11 \%$ ). Cinco de ellas son del Partido Unidad Social Cristiana (PUSC), tres del Partido Liberal Nacionalista (PLN) y una del partido Palmares Primero. De las siete provincias, en Alajuela se alzaron con el triunfo tres candidatas; dos en San José; una en Cartago, Heredia, Guanacaste y Puntarenas, y en Limón ninguna mujer fue electa (Artavia y Arias, 2020). Un rasgo que destaca en el contexto centroamericano es que casi todas las alcaldesas cuentan con una profesión; de las ocho con estudios de licenciatura, cinco se dedicaban a la educación, una al servicio médico y tres provenían del área administrativa. Solo una contaba con un secretariado bachiller (ver Tabla 5).

Tabla 5. Perfil de alcaldesas de Costa Rica electas en 2020

\begin{tabular}{|c|c|c|c|c|c|c|c|}
\hline \multirow{3}{*}{$\begin{array}{c}\text { Nombre } \\
\text { Katerine Ramírez González }\end{array}$} & \multirow{3}{*}{$\begin{array}{c}\text { Estudios } \\
\text { dmin. Educativa }\end{array}$} & \multicolumn{3}{|c|}{ Experiencia } & \multirow{2}{*}{\multicolumn{2}{|c|}{$\begin{array}{l}\text { (R) } \\
\text { Elección }\end{array}$}} & \multirow{3}{*}{$\begin{array}{l}\begin{array}{l}\text { Perfil de } \\
\text { alcaldesa }\end{array} \\
\text { oca exp. }\end{array}$} \\
\hline & & \multirow{2}{*}{$\begin{array}{l}\text { Ep } \\
X\end{array}$} & \multirow{2}{*}{ Eb } & \multirow{2}{*}{$\begin{array}{l}\text { Esc } \\
X\end{array}$} & & & \\
\hline & & & & & No & 1 & \\
\hline Aura Yamileth López Obregón & Admin. Educativa & - & $x$ & $x$ & No & 1 & Poca exp. \\
\hline Ilse María Gutiérrez Sánchez & Admin. Educativa & $x$ & $x$ & $x$ & Sí & 2 & Experimentada \\
\hline Iris Cristina Arroyo Herrera & Lic. en Contaduría & - & $X$ & $x$ & No & 1 & Poca exp. \\
\hline Ana Lorena Rovira Gutiérrez & Secretariado & $\mathrm{x}$ & $x$ & - & Sí & 2 & Experimentada \\
\hline $\begin{array}{l}\text { Sandra Lissette Fernández } \\
\text { Quirós }\end{array}$ & $\begin{array}{l}\text { Bachiller en Admin. } \\
\text { de Recursos } \\
\text { Humanos }\end{array}$ & $x$ & $x$ & $x$ & Sí & 3 & Experimentada \\
\hline
\end{tabular}




\begin{tabular}{llllllll}
\hline Ana L. Hernández González & Médica cirujana & - & $X$ & $X$ & Sí & 2 & Experimentada \\
\hline Eva Vásquez Vásquez & Profesora & - & - & $X$ & No & 1 & Ciudadana \\
\hline Patricia Bolaños Murillo & Profesora & $X$ & $X$ & $X$ & Sí & 2 & Experimentada \\
\hline
\end{tabular}

* (Ep) Experiencia política, (Eb) Experiencia burocrática y (Esc) Experiencia social o comunitaria. Fuente: elaboración propia con información de Unión Nacional de Gobiernos Locales (2020), Tribunal Electoral Supremo de Elecciones (2020) y Artavia y Arias (2020).

Cinco alcaldesas electas en Costa Rica son experimentadas (55.5\%) por contar con amplia trayectoria política, en principio por haber sido reelectas en por lo menos en una ocasión. Entre ellas destaca Sandra Lissette Fernández, que en 2020 inició su tercer periodo de gobierno. Lo sobresaliente es que han ocupado varios cargos en el aparato burocrático nacional y local, en el Ministerio de Educación Pública o en el Sistema de Salud. Patricia Bolaños Murillo fue funcionaria partidista y coordinadora de campaña del PUSC y Ana Lorena Rovira trabajó como auxiliar de contabilidad y administradora tributaria en Tarrazú. Por otro lado, de las que tienen poca experiencia, dos se dedicaban a la labor docente, en donde tendieron lazos con la comunidad y con la actividad partidista; por ejemplo, Katerine Ramírez fue secretaria del partido local Palmares Primero, mientras que Eva Vásquez trabajó con instituciones educativas y realizaba labor social de forma permanente.

\section{Panamá}

En las elecciones distritales de 2019 para renovar los 81 consejos municipales, en Panamá, fueron electas como alcaldesas doce mujeres (el $14.8 \%$ ). Seis pertenecían al Partido Revolucionario Democrático (PRD), cinco a Cambio Democrático (CD) y una al Partido Popular (PP). En cuanto al nivel de estudios, diez contaban con estudios técnicos o profesionales, de las cuales dos tenían el grado de maestría (Paula María González y Vielka Gálvez). El mayor contraste con los otros países de la región es el bajo número de alcaldesas experimentadas y reelectas; solo Yesenia Romero había ocupado un cargo en el Ministerio de Obras Públicas, Paula María González había trabajado como notaria pública y asesora en el Tribunal Electoral, y Jannelle González Logreira fue la única alcaldesa que repitió en el cargo. No obstante, sí había un gran número de profesionistas, la mayoría se dedicaba a la docencia, y las demás a otras disciplinas: ingenieras, abogadas, contadoras, médicas o biólogas (ver Tabla 6).

Tabla 6. Perfil de alcaldesas de Panamá electas en 2019

\begin{tabular}{|c|c|c|c|c|c|c|c|}
\hline \multirow{2}{*}{ Nombre } & \multirow{2}{*}{ Estudios } & \multicolumn{3}{|c|}{ Experiencia } & \multirow{2}{*}{\multicolumn{2}{|c|}{$\begin{array}{l}\text { (R) } \\
\text { Elección }\end{array}$}} & \multirow{3}{*}{$\begin{array}{l}\text { Perfil de alcaldesa } \\
\text { Experimentada }\end{array}$} \\
\hline & & Ep & Eb & Esc & & & \\
\hline Yesica Romero García & Ingeniera Industrial & $x$ & $x$ & - & No & 1 & \\
\hline $\begin{array}{l}\text { Paula María González } \\
\text { Ferreiro }\end{array}$ & $\begin{array}{l}\text { Lic. Derecho } \\
\text { y Maestría en } \\
\text { Derecho }\end{array}$ & $x$ & $x$ & $x$ & No & 1 & Experimentada \\
\hline Eneida Mendoza Soto & $\begin{array}{l}\text { Técnica en } \\
\text { Enfermería }\end{array}$ & $x$ & - & $x$ & No & 1 & Ciudadana \\
\hline
\end{tabular}




\begin{tabular}{|c|c|c|c|c|c|c|c|}
\hline Jesenka M. Espinosa Río & $\begin{array}{l}\text { Lic. Biología e } \\
\text { Ingeniera Industrial }\end{array}$ & - & $x$ & - & No & 1 & Poca exp. \\
\hline Vielka Gálvez Ballesteros & $\begin{array}{l}\text { Lic. en Educación } \\
\text { Mtra. en Docencia } \\
\text { Superior }\end{array}$ & - & $x$ & $x$ & No & 1 & Poca exp. \\
\hline $\begin{array}{l}\text { Jannelle Dadineth González } \\
\text { Logreira }\end{array}$ & $\begin{array}{l}\text { Pasante Lic. en } \\
\text { Mercadeo }\end{array}$ & - & $x$ & - & Sí & 2 & Experimentada \\
\hline $\begin{array}{l}\text { Magaly G. Ricord de } \\
\text { Sandoval }\end{array}$ & Sin profesión & $X$ & $x$ & - & No & 1 & Poca exp. \\
\hline $\begin{array}{l}\text { María Elena Sánchez } \\
\text { Martínez }\end{array}$ & $\begin{array}{l}\text { Lic, en } \\
\text { Programación, } \\
\text { Análisis y Diseño } \\
\text { de Sistemas }\end{array}$ & - & $x$ & $x$ & No & 1 & Poca exp. \\
\hline Felicia Gallego & Sin profesión & - & $x$ & $x$ & No & 1 & Ciudadana \\
\hline Rosalía Ellis Santos & $\begin{array}{l}\text { Téc. Registro } \\
\text { Médico }\end{array}$ & - & $x$ & $x$ & No & 1 & Ciudadana \\
\hline Nicolasa Jiménez & $\begin{array}{l}\text { Maestra en } \\
\text { Educación Primaria }\end{array}$ & $X$ & - & $X$ & No & 1 & Poca exp. \\
\hline Inés Carpintero Jiménez & Profesora & - & $x$ & $x$ & No & 1 & Ciudadana \\
\hline
\end{tabular}

* (Ep) Experiencia política, (Eb) Experiencia burocrática y (Esc) Experiencia social o comunitaria. Fuente: elaboración propia con información de Arauz (2019), Espinosa (2018) y Asociación de Municipios de Panamá (2020).

Cabe señalar que la mayoría de alcaldesas electas en Panamá tiene un perfil de poca experiencia política o "ciudadana", lo que se explica porque su actividad principal es la docencia, el trabajo administrativo o la labor social y comunitaria. La información indica una baja intervención en el aparato burocrático o en la estructura partidista; solo destacan en este aspecto Eneida Mendoza, quien formó parte del Frente Femenino del PRD, Magaly Glicel Ricord, que fue dirigente en Taboga, y Nicolasa Jiménez, que realizó trabajo político desde 2004. Se subraya la experiencia laboral como auxiliares o asistentes para empresas privadas o públicas.

\section{Nicaragua}

Las mujeres electas en Nicaragua en las elecciones de 2017 fueron 65 en los 153 municipios (el $42.5 \%$ ), por lo que se constituye en el país con mayor número y porcentaje de alcaldesas en Centroamérica, ello en un contexto político en donde el Frente Sandinista de Liberación Nacional (FSLN) es predominante, de ahí que solo la alcaldesa de Wiwilí de Jinotega, Reyna Esmeralda Hernández Mairena (después destituida), era del Partido Liberal Nacionalista (PLN). Un dato sobresaliente es que la mayoría de las alcaldesas (40) son experimentadas (el $61.5 \%$ ), cuentan con trayectoria como vicealcaldesas, concejalas o en la administración municipal, y han sido reelectas en el cargo por dos o tres ocasiones. En cuanto al nivel de estudios, 42 tienen estudios profesionales, destacan las profesoras, abogadas, médicas, contadoras e ingenieras (ver Tabla 7). Un rasgo distintivo en las alcaldesas de Nicaragua es el vínculo directo con la 
estructura partidista y de gobierno del FSLN, que es el factor de mayor oportunidad para ser candidatas; por ejemplo, Reyna Juanita Ramírez, quien ganó en Managua, la capital, está fuertemente vinculada al secretario general del partido.

Tabla 7. Perfil de alcaldesas de Nicaragua electas en 2017

\begin{tabular}{|c|c|c|c|c|c|c|c|}
\hline \multirow{3}{*}{$\begin{array}{l}\text { Nombre } \\
\text { ka Espinoza Peña }\end{array}$} & \multirow{3}{*}{$\begin{array}{l}\text { Estudios* } \\
\text { Licenciada }\end{array}$} & \multicolumn{3}{|c|}{ Experiencia** } & \multirow{2}{*}{\multicolumn{2}{|c|}{$\begin{array}{l}\text { (R) } \\
\text { Elección }\end{array}$}} & \multirow{3}{*}{$\begin{array}{c}\begin{array}{c}\text { Perfil de } \\
\text { alcaldesa }\end{array} \\
\text { Experimentada }\end{array}$} \\
\hline & & \multirow{2}{*}{$\begin{array}{l}\text { Ep } \\
X\end{array}$} & \multirow{2}{*}{$\begin{array}{c}\text { Eb } \\
X\end{array}$} & \multirow{2}{*}{$\begin{array}{l}\text { Esc } \\
-\end{array}$} & & & \\
\hline & & & & & Sí & 2 & \\
\hline $\begin{array}{l}\text { Frezzva Emelina Sobalvarro } \\
\text { Saravia }\end{array}$ & Sin profesión & $x$ & $x$ & $x$ & Sí & 2 & Experimentada \\
\hline Elizabeth Bermúdez Obando & Sin profesión & $X$ & $X$ & $x$ & Sí & 2 & Experimentada \\
\hline Lesbia Regina Palacios Solís & Profesora & $x$ & $x$ & $x$ & Sí & 2 & Experimentada \\
\hline Karla Licinia Delgado Chávez & $\begin{array}{l}\text { Lic. en Filología y } \\
\text { Comunicación }\end{array}$ & $x$ & $x$ & - & Sí & 2 & Experimentada \\
\hline Julinda del Socorro Téllez Ampie & Lic. en Derecho & $x$ & $x$ & - & Sí & 2 & Experimentada \\
\hline Yamilet Fonseca Téllez & Sin profesión & $x$ & $x$ & - & No & 1 & Poca exp. \\
\hline Fanny Francisca Zambrana García & Sin profesión & $x$ & $x$ & - & No & 1 & Poca exp. \\
\hline Aura Lyla Padilla Álvarez & Licenciada & $x$ & $x$ & - & Sí & 2 & Experimentada \\
\hline Bertha Lorena Jarquín Estrada & Sin profesión & $X$ & $X$ & - & No & 1 & Poca exp. \\
\hline M. del Transito Guevara Rodas & Sin profesión & $x$ & $x$ & $x$ & Sí & 2 & Experimentada \\
\hline Lyliam del R. Mayorga Torrez & Sin profesión & $\mathrm{x}$ & $\mathrm{x}$ & - & No & 1 & Poca exp. \\
\hline Nelly Marina García Molina & Ingeniera & $X$ & $X$ & $x$ & Sí & 2 & Experimentada \\
\hline María Cervanda Ruiz Delgadillo & Licenciada & $x$ & $x$ & - & No & 1 & Poca exp. \\
\hline Cenelia del Socorro Ocon Ruiz & Profesora & $x$ & $X$ & $x$ & Sí & 2 & Experimentada \\
\hline $\begin{array}{l}\text { Claribel del Rosario Castillo } \\
\text { Úbeda }\end{array}$ & $\begin{array}{l}\text { Ciencias de la } \\
\text { Educación y Mtra. } \\
\text { en Investigación } \\
\text { e Intervención } \\
\text { Social }\end{array}$ & - & $x$ & $x$ & Sí & 2 & Experimentada \\
\hline Zeneyda Sevilla Sequeira & Sin profesión & $x$ & $X$ & - & No & 1 & Poca exp. \\
\hline $\begin{array}{l}\text { Juana del Carmen Canales } \\
\text { Velásquez }\end{array}$ & Sin profesión & $x$ & $x$ & - & Sí & 2 & Experimentada \\
\hline Flora María Mendoza Irias & Sin profesión & $x$ & $x$ & - & Sí & 2 & Experimentada \\
\hline Brendaly Molina Cruz & Sin profesión & $x$ & $x$ & - & Sí & 2 & Experimentada \\
\hline $\begin{array}{l}\text { Catalina de los Ángeles Maltez } \\
\text { Narváez }\end{array}$ & $\begin{array}{l}\text { Secretariado } \\
\text { Técnico Medio. } \\
\text { Lic. en Admón. }\end{array}$ & $x$ & $x$ & - & Sí & 2 & Experimentada \\
\hline Sandra Rosa Vásquez López & Sin profesión & $X$ & $X$ & $x$ & Sí & 3 & Experimentada \\
\hline
\end{tabular}




\begin{tabular}{|c|c|c|c|c|c|c|c|}
\hline Julia de La Cruz Mena Rivera & $\begin{array}{l}\text { Lic. en Ciencias } \\
\text { Educación y Mtra. } \\
\text { en Administración }\end{array}$ & $x$ & $x$ & $x$ & Sí & 2 & Experimentada \\
\hline María Aminta López Rodríguez & Lic. Forestal & - & - & $x$ & No & 1 & Ciudadana \\
\hline Norma Ramona Herrera Zeledón & Profesora & $x$ & $x$ & - & Sí & 2 & Experimentada \\
\hline $\begin{array}{l}\text { Reyna Esmeralda Hernández } \\
\text { Mairena }\end{array}$ & Sin profesión & $x$ & - & $x$ & No & 1 & Poca exp. \\
\hline Aida Luz Altamirano Ruiz & $\begin{array}{l}\text { Contadora } \\
\text { pública }\end{array}$ & $x$ & - & $x$ & No & 1 & Ciudadana \\
\hline Rosa Amelia Valle Vargas & $\begin{array}{l}\text { Contadora } \\
\text { pública }\end{array}$ & $x$ & $x$ & $x$ & Sí & 3 & Experimentada \\
\hline Isidra Isabel Donaire Vallejos & Licenciada & $x$ & $x$ & - & No & 1 & Poca exp. \\
\hline Marbelys Ríos Miranda & Ingeniera & $x$ & $x$ & - & Sí & 2 & Experimentada \\
\hline Luz Amparo García García & Lic. en Biología & $x$ & $x$ & $x$ & Sí & 3 & Experimentada \\
\hline Dania S. Martínez Mondragón & $\begin{array}{l}\text { Lic. en Trabajo } \\
\text { Social }\end{array}$ & $x$ & $x$ & - & No & 1 & Poca exp. \\
\hline Bernarda Castillo Centeno & $\begin{array}{l}\text { Lic. en Ciencias } \\
\text { Educación }\end{array}$ & $x$ & $x$ & $x$ & Sí & 3 & Experimentada \\
\hline Adelayda Carrión Rodríguez & Licenciada & - & $x$ & $x$ & No & 1 & Poca exp. \\
\hline Reyna Juanita Rueda Alvarado & $\begin{array}{l}\text { Lic. en Admón. } \\
\text { Empresas }\end{array}$ & $x$ & $x$ & $x$ & No & 1 & Experimentada \\
\hline María Isabel Ramírez Orozco & Licenciada & $x$ & $x$ & - & No & 1 & Poca exp. \\
\hline Ligia Verónica Ramírez Torres & $\begin{array}{l}\text { Doctora en } \\
\text { Medicina }\end{array}$ & $x$ & $x$ & $x$ & Sí & 2 & Experimentada \\
\hline Aura Lila Blas Hernández & Lic. en Educación & - & $x$ & $x$ & No & 1 & Poca exp. \\
\hline Gioconda del S. Aguirre Ticay & $\begin{array}{l}\text { Doctora en } \\
\text { Medicina }\end{array}$ & $x$ & - & $x$ & No & 1 & Ciudadana \\
\hline Gloria María Sánchez Munguía & Sin profesión & - & - & $x$ & No & 1 & Poca exp. \\
\hline $\begin{array}{l}\text { Clarissa Esmeralda Vivas } \\
\text { Castellón }\end{array}$ & $\begin{array}{l}\text { Médica cirujana } \\
\text { dentista }\end{array}$ & $x$ & $x$ & $x$ & Sí & 3 & Experimentada \\
\hline Martha Janeth Pérez García & Admón. Empresas & $x$ & $x$ & - & Sí & 2 & Experimentada \\
\hline $\begin{array}{l}\text { Brenda del Carmen Jiménez } \\
\text { Urbina }\end{array}$ & $\begin{array}{l}\text { Sin profesión } \\
\text { (artesana) }\end{array}$ & $x$ & - & $x$ & Sí & 2 & Experimentada \\
\hline María Lesbia Treminio Chavarría & Profesora & $x$ & $x$ & $x$ & Sí & 2 & Experimentada \\
\hline Hilda Espinoza Urbina & $\begin{array}{l}\text { Lic. en Biología } \\
\text { y Ciencias } \\
\text { Naturales }\end{array}$ & $x$ & $x$ & - & No & 1 & Poca exp. \\
\hline María Isabel González Amador & Profesora & - & $x$ & $x$ & Sí & 2 & Experimentada \\
\hline $\begin{array}{l}\text { Martha Azucena Bucardo } \\
\text { Polanco }\end{array}$ & Licenciada & $x$ & - & - & No & 1 & Poca exp. \\
\hline
\end{tabular}




\begin{tabular}{|c|c|c|c|c|c|c|c|}
\hline Consuelo María Moran Lorente & Ingeniera & - & $x$ & $x$ & No & 1 & Ciudadana \\
\hline María Daniela Martínez Jarquín & Profesora & $x$ & $x$ & $x$ & Sí & 2 & Experimentada \\
\hline Mirna Yesenia Pérez Quiñonez & Sin profesión & $x$ & - & - & No & 1 & Poca exp. \\
\hline Carla Meléndez Almendarez & Sin profesión & $x$ & $x$ & - & Sí & 2 & Experimentada \\
\hline Thelma María Olivas Ardon & Profesora & $x$ & $x$ & $x$ & Sí & 3 & Experimentada \\
\hline Lisseth Areliz Valladares Vílchez & Licenciada & $x$ & $x$ & - & No & 1 & Poca exp. \\
\hline Consuelo de Jesús Rivera & Sin profesión & $x$ & $x$ & $x$ & Sí & 2 & $\begin{array}{l}\text { Experimentada } \\
\text { Ciudadana }\end{array}$ \\
\hline Xiomara Tercero López & Licenciada & $x$ & $x$ & - & Sí & 2 & Experimentada \\
\hline María Frodelina Bobb Flores & Licenciada & $X$ & - & $x$ & No & 1 & Poca exp. \\
\hline Rose Marie Cunningham Kain & $\begin{array}{l}\text { Sin profesión } \\
\text { (indígena) }\end{array}$ & $x$ & - & $x$ & No & 1 & Ciudadana \\
\hline $\begin{array}{l}\text { Carolina De Fátima Morgan } \\
\text { Mendoza }\end{array}$ & Doctora & $x$ & $x$ & - & No & 1 & Poca exp. \\
\hline Eda Griselda Medina Campos & $\begin{array}{l}\text { Abogada y } \\
\text { maestra }\end{array}$ & $x$ & $x$ & $x$ & Sí & 3 & Experimentada \\
\hline Ana Clemencia Ávalos Ramírez & Lic. en Derecho & $x$ & $x$ & $x$ & Sí & 3 & Experimentada \\
\hline Aurora Elena Álvarez Álvarez & Licenciada & $x$ & $x$ & - & No & 1 & Experimentada \\
\hline Ana Patricia Padilla Cortez & Licenciada & $x$ & $x$ & - & Sí & 2 & Experimentada \\
\hline María Estela Centeno Silva & Licenciada & $x$ & $x$ & - & Sí & 2 & Experimentada \\
\hline Gilma Victoria Canales Cruz & Lic. en Derecho & $x$ & $x$ & $x$ & Sí & 3 & Experimentada \\
\hline Mayra del Socorro Solís Briceño & Lic. en Educación & - & - & $x$ & No & 1 & Ciudadana \\
\hline
\end{tabular}

* En algunos casos no se encontraron datos sobre la carrera profesional. La información publicada por los gobiernos municipales, el partido político FSLN y las redes sociales de las candidatas solo señalan el nivel de licenciatura, pero no la especialidad.

** (Ep). Experiencia política, (Eb) Experiencia burocrática y (Esc) Experiencia social o comunitaria.

Fuente: elaboración propia con información de La Gaceta. Diario Oficial (2017) y Cerda (2018).

Las alcaldesas con poca experiencia, antes de ser postuladas, tenían un cargo administrativo en el municipio, habían sido vicealcaldesas o concejalas, o bien realizaban trabajo político para el partido en el gobierno. De las seis ciudadanas, destacan Consuelo de Jesús Rivera (de Mozonte) y Rose María Connighan (de Waspan), ambas con trabajo comunitario en territorios indígenas (González, E., 2018). Entre las más experimentadas destacan Sandra Rosa Vásquez, Rosa Amelia Valle, Luz Amparo García, Bernarda Castillo, Clarissa Esmeralda Vivas, Thelma María Olivas, Eda Griselda Medina, Ana Clemencia Avalos y Gilma Victoria Canales, quienes asumieron sus cargos por tercera ocasión. Julia de la Cruz Rivera fue vicepresidenta y presidenta del Partido Liberal Independiente (PLI), diputada y dos veces alcaldesa de Granada. El impulso de políticas de igualdad de género del FSLN (Mayoral, 2012) ha propiciado mayor participación de las mujeres como alcaldesas, aunque ancladas a la estructura clientelar-populista del gobierno. 


\section{Comparativo sobre el perfil de las alcaldesas de Centroamérica}

En el análisis sobre la experiencia y trayectoria política de las alcaldesas en Centroamérica encontramos que en cuatro países - Belice, Honduras, Nicaragua y Costa Rica- predominan las alcaldesas experimentadas; en El Salvador hay un equilibrio entre los tres perfiles, mientras que en Guatemala y Panamá lo que despunta es el porcentaje de alcaldesas poco experimentadas. En cuanto a las ciudadanas, en Panamá y Belice representan un tercio del total; en Honduras son más las ciudadanas que las poco experimentadas, y en Nicaragua y Costa Rica apenas llegan al 10 \% (ver Gráfica 1). Belice es el único país que no tiene alcaldesas poco experimentadas, lo cual es muy relativo debido al número reducido de casos analizados, solo tres.

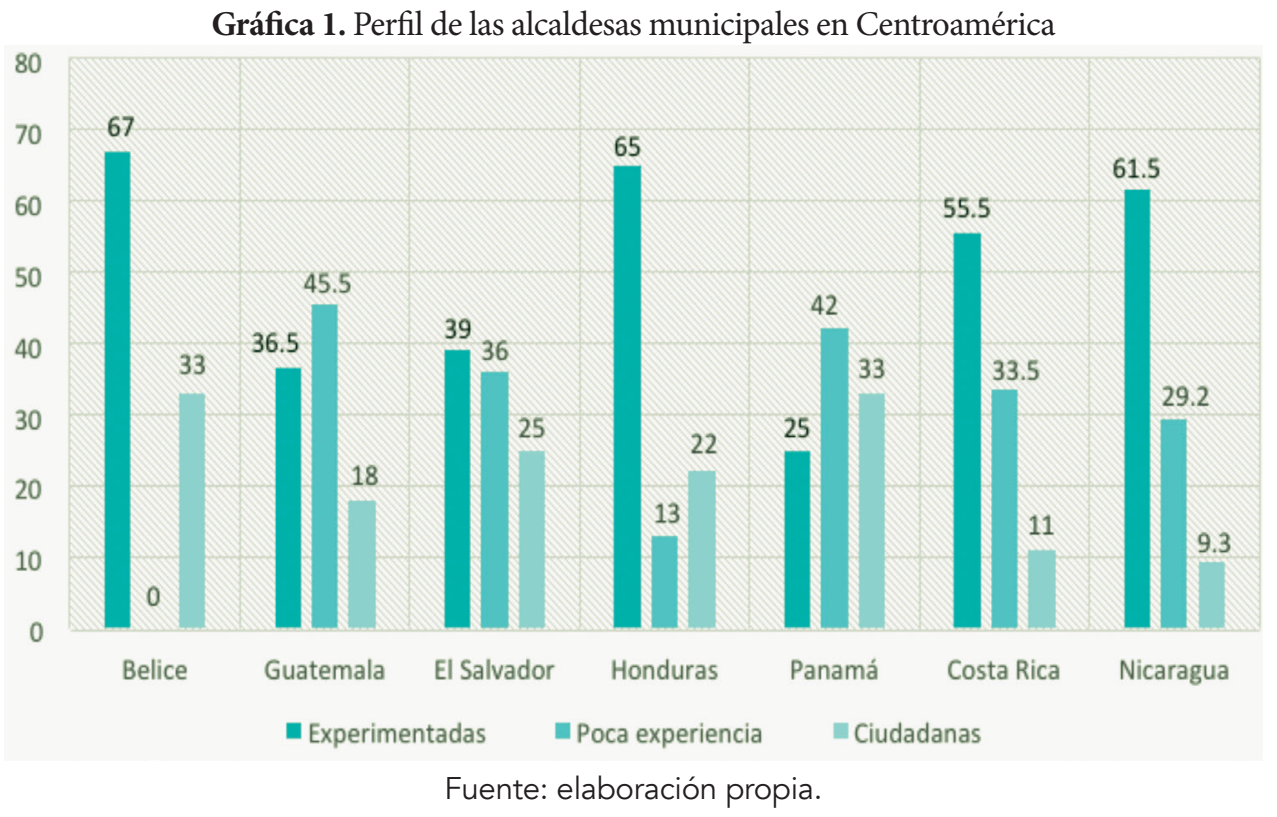

En Belice y Honduras, un factor que determina la amplia trayectoria y experiencia de las alcaldesas es que han ocupado el cargo en más de una ocasión, incluso en algunos casos hasta tres veces seguidas; en Nicaragua es notorio que, además de haber sido alcaldesas, vicealcaldesas o concejalas, las mujeres electas cuentan con trabajo político-electoral y comunitario en el FSLN, mientras que en Costa Rica es el trabajo como profesionistas (profesoras, contadoras o médicas), además de participar en cargos burocráticos dentro de la estructura estatal, lo que las distingue. En El Salvador, el universo se divide en tres tercios: experimentadas (39\%), con poca experiencia (36\%) y ciudadanas (25\%), debido al importante número de alcaldesas que se ocupaban en actividades profesionales y en organizaciones sociales o comunitarias; en Guatemala y Panamá, por su parte, la poca experiencia de las alcaldesas se debe, principalmente, a que influye en su postulación la actividad profesional, social y comunitaria, más que el trabajo partidista o en la burocracia municipal. 
Los indicadores que permiten diferenciar los tipos de perfiles políticos de las alcaldesas son cuatro: 1) el grado de adhesión al partido político; 2) la trayectoria social o política; 3) los vínculos de poder establecidos, y 4) la posibilidad de reelección. Los criterios de diferenciación son:

1) El grado de adhesión al partido político es la intensidad del vínculo que tienen las alcaldesas con los partidos políticos. Las experimentadas son miembros o dirigentes que ocupan cargos de dirección en la estructura partidista; las poco experimentadas son militantes que realizan trabajo permanente en el partido y en campañas electorales, mientras que las ciudadanas son simpatizantes, caracterizadas por identificarse con algún partido y posiblemente manifestar su preferencia, aunque no suelen estar afiliadas a los partidos.

2) La trayectoria está definida por la experiencia profesional, política o social que han desarrollado. Las experimentadas, además de desarrollar su ejercicio profesional, han ocupado cargos de dirección en los partidos políticos, principalmente en el nivel local, y se han desempeñado en cargos de elección o dirección burocrática; las poco experimentadas trabajan para un partido y han sido postuladas, como suplentes, a cargos de elección, además de que laboran en la estructura burocrática municipal, y las ciudadanas, por su lado, destacan por su trabajo social, gremial o comunitario.

3) Los vínculos de poder están referidos a los lazos de unión que tienen con grupos, partidos, familias o personas con poder. Las experimentadas suelen pertenecer a familias de autoridad, por ende, suelen ser arropadas por los círculos de poder, los partidos o grupos políticos; las poco experimentadas, por carecer de vínculos con familias de poder, suelen establecer lazos con dirigentes partidistas o líderes políticos regionales o locales; las ciudadanas, por su parte, están estrechamente relacionadas con la comunidad o el sector social al que pertenecen, y su inclusión política se debe al prestigio y al capital social alcanzado.

4) La reelección se refiere a la posibilidad de permanecer en el cargo de alcaldesas mediante la evaluación ciudadana a través del sufragio. Las experimentadas frecuentemente son ratificadas en el cargo por su experiencia, pero también por el apoyo partidista y los vínculos de poder establecidos; las poco experimentadas se reeligen en forma ocasional debido al trabajo realizado y al apoyo recibido por parte del partido político, mientras que las ciudadanas son reelectas excepcionalmente ya que dependen casi exclusivamente de su desempeño en el cargo.

De esta forma, como se registra en la Tabla 8, las alcaldesas experimentadas suelen ser dirigentes de sus partidos políticos, cuentan con amplia trayectoria profesional, política y burocrática, pertenecen a familias o grupos de poder y frecuentemente son reelectas. Las poco experimentadas son militantes en los partidos políticos, realizan trabajo de organización y propaganda política, están vinculadas a dirigentes partidistas y es poco frecuente su reelección. Las ciudadanas, finalmente, suelen no estar afiliadas a los partidos políticos, aunque simpatizan con alguno, se caracterizan por su labor social, gremial o comunitaria, a la que están fuertemente vinculadas, y su posibilidad de mantenerse en el cargo es excepcional. 
Tabla 8. Características generales de perfil de alcaldesas en Centroamérica

\begin{tabular}{lllll}
\multicolumn{1}{c}{ Perfil } & \multicolumn{1}{c}{$\begin{array}{c}\text { Adhesión a un } \\
\text { partido }\end{array}$} & Trayectoria & Vinculos de poder & Reelección \\
\hline Experimentada & Miembros/dirigentes & $\begin{array}{l}\text { Profesional, política y } \\
\text { burocrática }\end{array}$ & Familiares & Frecuente \\
\hline Poco experimentada & Militantes/activistas & Activista en partido político & Dirigente partidista & Esporádica \\
\hline Ciudadana & Simpatizantes & Trabajo social o comunitario & Con la comunidad & Excepcional \\
\hline
\end{tabular}

Fuente: elaboración propia.

Una de las áreas de oportunidad para que las mujeres participen en la política como alcaldesas sigue siendo a través de los partidos políticos. Como refiere María José Cascante:

A nivel local los partidos políticos continúan teniendo un monopolio de la competencia por las elecciones locales. Con tres excepciones importantes en Honduras y en Panamá donde se permiten las candidaturas independientes y en Guatemala donde se permite la competencia de comités cívicos electorales [...], en el resto de los países los partidos dominan la competencia (Cascante, 2018, p. 18).

Ello revela mayor dificultad para las alcaldesas ciudadanas y mejores perspectivas para las experimentadas, máxime en regímenes políticos con estructuras político-clientelares.

En cuanto a la preparación académica y la experiencia profesional, destaca el porcentaje elevado de profesionistas que ocupan el cargo, principalmente del área social-administrativa (abogadas, maestras y contadoras), pero también del área de la salud y disciplinas técnicas (médicas, ingenieras o biólogas). La mayor cantidad de profesionistas se encuentra en Costa Rica, seguido de Panamá; en ambos países sobresalen las profesoras, quienes dejaron las aulas para ocupar la oficina principal en la alcaldía, así como las especialistas en salud y contadoras. En Nicaragua y El Salvador se reportó un número importante de profesionistas, lo cual se explica porque el FSLN, ARENA y el FMLN han sabido captar a profesionistas de distintas áreas en su estructura clientelar-partidista. En Belice y Guatemala, países con menor porcentaje de alcaldesas, participan un número reducido de maestras, administradoras y contadoras. La actividad profesional parece estar asociada con la postulación al cargo de la alcaldía municipal.

La capacidad de las mujeres para establecer vínculos tempranos con los grupos de poder, por motivos de parentesco, de amistad, laboral o social, es una opción viable para que ellas puedan alcanzar un mayor empoderamiento. Formar parte de las redes de poder en los países centroamericanos es un plus para que las mujeres puedan ser consideradas, en igualdad de oportunidad que los varones, para encabezar los gobiernos municipales; pero no solo a través de los lazos con familias de poder con grupos o líderes políticos, sino también con organizaciones sociales, gremiales o comunales, que de igual modo aportan el capital social para asumir una candidatura y ocupar el cargo. Sin embargo, también se debe avanzar en superar la dependencia de las mujeres con los vínculos de parentesco, principalmente con varones, ya que en muchas ocasiones su postulación o sustitución, como en el caso de "las Juanitas" en México, representa un obstáculo para romper el techo de cristal imperante en nuestros países y acentúa el problema de la violencia política en contra de las mujeres. 
La reelección, finalmente, como medio reconocido para evaluar el desempeño de quienes se dedican a la función pública, es un ejercicio electoral a través del cual la ciudadanía, mediante su voto, ratifica o retira el apoyo al alcalde o alcaldesa; es un mecanismo electoral muy generalizado en las elecciones de Centroamérica y muy poco desarrollado en otros países, como México, en donde su implementación es reciente (desde 2014). El índice elevado de mujeres que han repetido en el cargo en Belice, Honduras, Nicaragua y Costa Rica es un indicador de la buena valoración ciudadana sobre el desempeño de las alcaldesas; cabe señalar que en algunos casos han gobernado sus municipios hasta por once ocasiones (ver Gráfica 2). Salvo el caso de Panamá, que tiene poca frecuencia de mujeres reelectas, las alcaldesas en Centroamérica suelen estar bien calificadas para repetir en el cargo, lo que indica que, a pesar del bajo porcentaje de representación política que tienen las mujeres en el principal cargo municipal, hay una buena percepción sobre su desempeño público.

Gráfica 2. Reelección de las alcaldesas municipales en Centroamérica

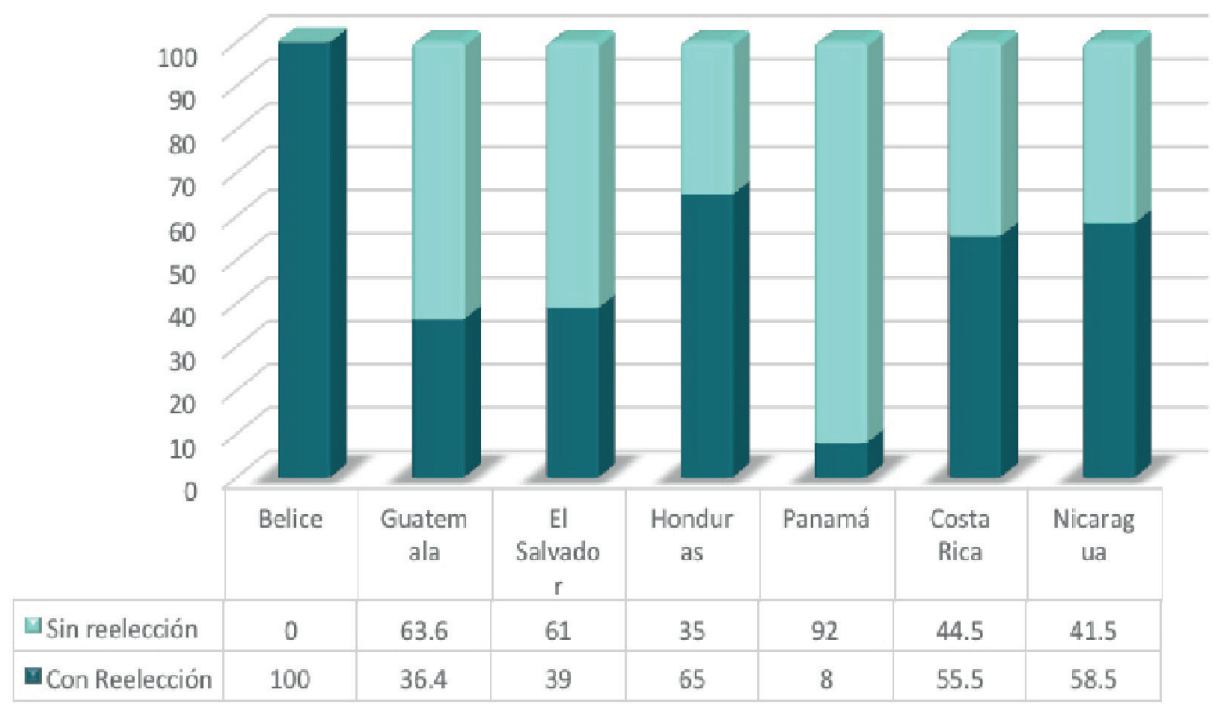

Fuente: elaboración propia.

\section{Conclusiones}

La participación política de las mujeres como alcaldesas en Centroamerica registra todavía un bajo nivel de representación en los gobiernos locales, por ello, la discusión se ha centrado en los factores institucionales (cuotas de género), económicos (desigualdad de oportunidades) y culturales (aspectos subjetivos) que imposibilitan alcanzar la equidad entre hombres y mujeres. De igual forma, son evidentes las diferentes formas de violencia política de género y la falta de información sobre las mujeres que ocupan cargos de alcaldesas, como se constató al tratar de encontrar datos sobre sus hojas de vida, tipo de profesión y trayectoria social y política que permitieran delinear su perfil, congruente con el contexto gubernativo de Centroamérica, región caracterizada por la presencia de países en proceso de reconstrucción democratica, fortalecimiento institucional, reconfiguración del sistema de partidos y cimentación ciudadana. 
El análisis de la situación y las circunstancias que viven las mujeres en Centroamérica, como profesionistas, activistas o ciudadanas; como dirigentes, militantes o simpatizantes partidistas; con vínculos familiares, políticos o sociales; con trabajo electoral, burocrático o comunitario; con mucha, poca o ninguna experiencia en tareas de gobierno, permitió definir tres tipos de perfiles: las experimentadas, poco experimentadas y ciudadanas. Se encontró que las experimentadas desarrollan actividades profesionales, cargos de dirección partidista y burocrática, cuentan con vínculos familiares de poder y son proclives a la reelección; las poco experimentadas tienen como rasgos distintivos la labor partidista y ocupar cargos en consejos municipales y en el gobierno local, mientras que las ciudadanas registran una trayectoria de trabajo comunitario, prestigio social y gestión de servicios.

Las alcaldesas en Centroamerica han sabido aprovechar los reducidos espacios de oportunidad para acceder al más alto cargo municipal, por lo que han procurado, cada vez más, relacionar la actividad profesional con la política, enrolarse en actividades partidistas, laborar en el servicio público municipal, postularse a cargos de elección, insertarse en redes de poder y beneficiarse de su experiencia en gestión, trabajo social y comunitario, todo lo cual les sirve para ganarse el voto ciudadano. En algunos casos es más relevante: la militancia partidista, como en Nicaragua, El Salvador y Guatemala; la actividad profesional, como en Costa Rica; el trabajo social y comunitario, como en Panamá, o la reelección consecutiva, como en Belice y Honduras.

El perfil de "alcaldesa ciudadana", que sintetiza la forma de participación de las mujeres en el ámbito municipal centroamericano, es pertinente porque recoge la experiencia de vida comunitaria y de labor social que realizan como resultado de varias décadas de guerra civil (Guatemala, el Salvador y Nicaragua) o de un incipiente establecimiento democrático (Honduras y Panamá). Esto teóricamente ayuda a comprender que, en cuanto a la participación política de las mujeres como alcaldesas, es necesario considerar, además de la trayectoria profesional y política, la praxis social y comunitaria. Otro factor relevante para entender la postulación de mujeres es la militancia partidista, sobre todo por la proliferación de partidos clientelares que controlan los espacios públicos a nivel local, sea del FSLN de Nicaragua, el FMLN y ARENA en El Salvador o el PLN y PAC en Costa Rica, por mencionar algunos.

En cuanto a los indicadores sobre el perfil de las alcaldesas en Centroamérica, destaca la reelección como factor principal para conocer la evaluación ciudadana sobre el desempeño de las mujeres en el cargo, sobre todo porque es una práctica común en la región. Es claro que los indicadores propuestos para definir el perfil profesional y político de las alcaldesas permiten acercarnos a la realidad política de las mujeres en la región, pero es importante reconocer que la complejidad centroamericana obliga a mejorar los esquemas de interpretación política; de igual forma, demanda que las instituciones gubernamentales, electorales, partidos políticos y candidatas mejoren los canales de información que permitan conocer mejor quiénes son las alcaldesas en nuestra América.

\section{Referencias}

Álvarez, L., Gómez-Abarca, C. J., Martínez, M., Méndez-Gómez, D. U., Nájera, E., Uc, P., y Solís J. (2019). Política y democracia en Centroamérica y México. Ensayos reunidos. Universidad de Ciencias y Artes de Chiapas.

Arauz, M. (2019). Alcaldes, representantes y concejales de Panamá 2019-2024. Asociación de Municipios de Panamá. https://amupa.org.pa/alcaldes-representantes-y-concejales-2019-2014/

Artavia, S., y Arias, G. (2020, 2 de febrero). Golpe al liderazgo femenino en alcaldías: solo 9 mujeres electas en comicios municipales 2020. La Nación. https:/www.nacion.com/data/golpe-al-liderazgo-femenino-enalcaldias-solo/VQBJ7GB2B5ERBKNN3CK4TDEW3M/story/ 
Asociación de Municipios de Panamá (2020). Listado general de autoridades municipales 2019-2024. https://amupa. org.pa/directorio-municipal-de-panama-2/

Bernal, D. (2016). Investigación sobre la participación política de las mujeres en Panamá. En C. Urquilla et al., Derechos politicos de las mujeres: avances y buenas prácticas en El Salvador, Costa Rica y Panamá (pp. 205-312). Instituto Interamericano de Derechos Humanos.

Bolaños, A. (2006). Las cuotas de participación política de La mujer en Costa Rica: 1996-2005. Revista de Derecho Electora, 1, 1-17. https://www.tse.go.cr/revista/art/1/bolanos.pdf

Caribbean Election (2020). Silvya Flores. En ceBiography. http://caribbeanelections.com/knowledge/biography/ bios/flores sylvia.asp

Cascante, M. J. (2018). Derecho electoral centroamericano. Revista Derecho Electoral, 16, 3-27.

Castellanos, J., y Romero, S. (2019). Encrucijadas de la democracia en Honduras y América Central. Instituto Universitario en Democracia, Paz y Seguridad.

Cedillo, R. (2016). La paridad de género en las elecciones locales de 2015 de Tabasco, Estado de México y Distrito Federal. LiminaR. Estudios Sociales y Humanísticos, XIV(1), 186-201. 10.29043/LIMINAR.V14I1.431

Cedillo, R. (2021). Participación política de la mujer como alcaldesa en Centroamérica. Las elecciones municipales de 2017-2020. Cuadernos Inter.c.a.mbio sobre Centroamérica y el Caribe, 18(1), 1-29. https://revistas. ucr.ac.cr/index.php/intercambio/article/view/45458

Cerda, A. (2018, 2 de febrero). Los alcaldes eternos. Alcaldes del gobernante FSLN y también del PLC y CXl se reeligen continuamente en sus cargos. Confidencial analiza la lista de los alcaldes eternos. confidencial.com. https://confidencial.com.ni/especiales/alcaldes-eternos/

Comisión Económica para América Latina y el Caribe (2013). Observatorio de Igualdad de Género de América Latina yel Caribe (OIG). Informe anual 2012: los bonos en la mira, aporte y carga para las mujeres. Naciones Unidas.

Comisión Interamericana de Mujeres (2016). La democracia paritaria en América Latina. Los casos de México y Nicaragua. Comisión Interamericana de Mujeres; Organización de Estados Americanos. https://www.oas. org/en/cim/docs/DemocraciaParitaria-MexNic-ES.pdf

Corporación de Municipalidades de la República de El Salvador (2020). Alcaldesas municipales de El Salvador. Consejo de Mujeres de El Salvador. https://www.comures.org.sv/html/agremiados/mujergobiernolocal.html

Espinosa, I. (2018, 11 de febrero). El grito de la mujer negäbe. El viaje. Proyecto Wakaya. https://www. proyectowakaya.com/tag/profesora/

Fernández, A. M. (2011). Las cuotas de género y la representación política femenina en México y América Latina. Argumentos, 66(24), 247-275. https://argumentos.xoc.uam.mx/index.php/argumentos/article/ view/295

Freidenberg, F. (2019). La representación política de las mujeres en Honduras: resistencias partidistas y propuestas de reformas inclusivas en perspectiva comparada. Centro Carter-Programa para América Latina y el Caribe.

Freidenberg, F., y Brown H. (2019). La representación política de las mujeres en Panamá: una propuesta para superar el dilema de coordinación entre las primarias y la paridad. Revista de Derecho Electoral, 27, 5-25. 10.35242/RDE_2019_27_1

Freidenberg, F., y Lajas S. (2014). De la cuota a la paridad: las reformas para mejorar la representación política de las mujeres en América Latina. Proyecto de Reformas Políticas en América Latina (1978-2015). Secretaría de Asuntos Políticos de la Organización de los Estados Americanos.

Funes, L. (2014). Honduras 2013: mujeres y elecciones. Monitoreo del cumplimiento de las leyes sobre la participación política de las mujeres en el proceso electoral del 24 de noviembre de 2013. Centro de Documentación de Honduras; Instituto Nacional Demócrata.

González-Oliva, X. (2018, 7 de marzo). Las 27 alcaldesas por partidos para el período 2018-2021. La cantidad de mujeres al frente de los Concejos Municipales aún es baja y no cambió respecto al período 2015-2018. El Salvador.com. https://historico.elsalvador.com/historico/458335/las-mujeres-gobernaran-una-de-cada-10alcaldias.html

González-Villarreal, C. (2017). Estudio de contexto: situación de los municipios en Centroamérica y requerimientos en formación en gestión pública municipal. Centro de Investigación y Evaluación Institucional; Universidad Estatal y a Distancia.

González, A. L. (2019, 23 de junio). El pulso ganado por once alcaldesas. Fueron once las mujeres que obtuvieron la vara edil en estas elecciones. Una más que las pasadas elecciones. El Periódico. https://Elperiodico.Com. Gt/Nacion/2019/06/23/El-Pulso-Ganado-Por-Once-Alcaldesas/ 
González, E. (2018, 25 de enero). Asumen sus cargos nuevas autoridades municipales de Waspam. Tn8.canal joven de Nicaragua. https://www.tn8.tv/departamentos/442091-asumen-cargos-nuevas-autoridadesmunicipales-waspam/

Herrera, M. S. (coord.) (2010). Democracia en Centroamérica: más hombres asumiendo las tareas domésticas. Alianza Feminista Centroamericana para la Transformación de la Cultura Política Patriarcal.

Hoffmann, O. (2009). Elecciones y política en Belize, una exploración cartográfica. En E. Cunin y O. Hoffmann (coords.). Etnicidad y nación: debate alrededor de Belice (Cuaderno de Trabajo 5). Proyecto AFRODESC.

Instituto de Acceso a la Información Pública de El Salvador (2020). Alcaldías (183). Portal de Transparencia. https://www.transparencia.gob.sv/categories/5

Instituto Holandés para la Democracia Multipartidaria (2019). El techo de cristal. Barreras patriarcales a la participación política de las mujeres en Guatemala. Netherlands Institute for Multiparty Democracy. https:// centralamerica.nimd.org/wp-content/uploads/2019/03/El-Techo-de-Cristal.pdf

Instituto Salvadoreño de Desarrollo Municipal (2018). Directorio de las 262 municipalidades del período 2018 2021. Portal de Transparencia. https://www.transparencia.gob.sv/institutions/isdem

Krook, M. L. (2017). ¿Qué es la violencia política? El concepto desde la perspectiva de la teoría y la práctica. En F. Freidenberg y G. del Valle (ed.). Cuando hacer política te cuesta la vida. Estrategias contra la violencia política hacia las mujeres en América Latina (pp. 45-72). Universidad Nacional Autónoma de México-Instituto de Investigaciones Jurídicas; Tribunal Electoral de la Ciudad de México.

La Gaceta. Diario Oficial (2017, 20 de noviembre). Proclamación de electos. Listado de ciudadanos electoselecciones municipales 2017. http://legislacion.asamblea.gob.ni/normaweb.nsf/(\$All)/35E84FC07AB3510F 062581DF005ElEFl?OpenDocument

Letona, M. (2017, 14 de diciembre). Participación Política de las Mujeres en Centroamérica: Un reto regional y una deuda pendiente. Distintas Latitudes. https://distintaslatitudes.net/Historias/Reportaje/ParticipacionPolitica-Las-Mujeres-Centroamerica-Reto-Regional-Una-Deuda-Pendiente

Massolo, A. (2007). Participación política de las mujeres en el ámbito local en América Latina. Instituto Internacional de Investigaciones y Capacitación de las Naciones Unidas para la Promoción de la Mujer. https://iknowpolitics. org/sites/default/files/ambitio20local_3_0.pdf

Mayoral, M. J. (2012, 11 de marzo). Nicaragua: alcaldías con rostro y pensamiento de mujer. El 19 Digital, Nicaragua. https:/www.ell9digital.com/articulos/ver/titulo:880-nicaragua-alcaldias-con-rostro-ypensamiento-de-mujer

Medina, A. (2010). La participación política de las mujeres. De las cuotas de género a la paridad. Centro de Estudios para el Adelanto de las Mujeres y la Equidad de Género; Cámara de Diputados, LXI Legislatura.

Obando, A. E. (2016). Investigación sobre la participación política de las mujeres en Costa Rica. En C. Urquilla et al., Derechos políticos de las mujeres: avances y buenas prácticas en El Salvador, Costa Rica y Panamá (pp. 113-203). Instituto Interamericano de Derechos Humanos.

ONU Mujeres (2018). Participación política de las mujeres a nivel municipal: proceso electoral 2017-2018. https://www2. unwomen.org/-/media/field \%20office \%20mexico/documentos/publicaciones/2019/participacin \%20 poltica \%20de \%20las \%20mujeres \%20a \%20nivel \%20municipal_proceso \%20electoral \%202017_2018. pdf?la=es\&evs=3303

Palacio, M. (2009). A review of municipal elections in post-independent Belize. Edición de la autora. https://es.slideshare. net/MyrtleP/review-of-municipal-elections-in-postindependent-belize

Pasquino, G. (2004). La participación política. En Nuevo Curso de Ciencia Política (pp. 70-101). Fondo de Cultura Económica.

Programa de las Naciones Unidas para el Desarrollo (2012). Toward equality of opportunity for equality of results a situation. Analysis of Gender and Politics in Belize. Comisión Nacional de la Mujer; Programa de las Naciones Unidas para el Desarrollo.

Quinteja, C. (2020, 12 de febrero). Las diez alcaldesas. Participación política de las mujeres. AgenciaOcote.com. https:/www.agenciaocote.com/blog/2020/02/12/las-diez-alcaldesas/

Ramos, S. (2019, 12 de junio). Mujeres en corporaciones municipales: La tarea pendiente de los partidos políticos. Ojoconmipisto.com. http://www.ojoconmipisto.com/reeleccion2019/mujeres-en-corporacionesmunicipales/

Ríos, M. (2008). Introducción. En M. Ríos (ed.), Mujer y política. El impacto de las cuotas de género en América Latina (pp. 13-23). Catalonia; IDEA Internacional; FLACSO. 
Rodríguez, M., Arriaga, G. y Ángeles, M. I. (2013). Cultura democrática de género: discriminación, cuotas de género y simulación. Espacios Públicos, 16(38), 41-63.

Romero, S. (2016). La participación política femenina en los espacios de poder local: el reto de las nuevas fronteras. En C. Urquilla et al., Derechos políticos de las mujeres: avances y buenas prácticas en El Salvador, Costa Rica y Panamá (pp. 9-15). Instituto Interamericano de Derechos Humanos.

Sánchez, G. (2019, 20 de junio). Elecciones Guatemala/once mujeres son electas alcaldesas. República. https:// republica.gt/2019/06/20/elecciones-guatemala-alcaldesas/

Sosa, E. (2018). Enorme brecha de equidad de género en las elecciones de noviembre de 2017. Centro de Estudios para la Democracia; Federación Luterana Mundial.

Tello, F. M. (2009). La participación política de las mujeres en los gobiernos locales latinoamericanos: barreras y desafios para una efectiva democracia de género. Centro Latinoamericano de Formación Política Mujeres y Sociedad. http:// americalatinagenera.org/newsite/images/cdr-documents/publicaciones/participacion_mujeres_gob_ locales_flavia_mabel_tello.pdf

Torres, I. (2018). Violencia contra las mujeres en política. Investigación en partidos políticos de Guatemala. Instituto Nacional Demócrata.

Toussaint, M. (1990). Las elecciones en Belice: del espejismo bipartidista a la realidad neocolonialista. Secuencia, $18,5-16$.

Tribunal Electoral Supremo de Elecciones (2020). Elecciones municipales 2020. https://www.tse.go.cr/2020/ declaratorias.htm

Tribunal Superior de Elecciones (2018). Elecciones generales 2017. Municipios por partido y municipio. https:// eleccionesgenerales2017.tse.hn/

Tribunal Supremo Electoral de El Salvador (2018). Memoria especial. Elecciones 2018. Diputaciones legislativas y elecciones municipales. https://www.tse.gob.sv/documentos/memoria-de-elecciones/memoria-elecciones-2018.pdf

Unión Nacional de Gobiernos Locales (2020). Perfiles alcaldías 2020-2024. Elecciones municipales desde la Unión de Gobiernos Locales. Un proceso democrático histórico, Amprensa.com. https://amprensa.com/wpcontent/uploads/2020/02/Perfiles-Alcald \%C3 \%ADas-2020-2024_l.pdf

Urquilla, C. (2016). Promoción de la participación política de las mujeres en El Salvador. En C. Urquilla et al., Derechos políticos de las mujeres: avances y buenas prácticas en El Salvador, Costa Rica y Panamá (pp. 7-112). Instituto Interamericano de Derechos Humanos.

Valdés, E. (2007). El sistema político y electoral panameño y su influencia en la configuración del sistema de partidos. Justicia Electoral. Revista del Tribunal Electoral del poder judicial de la Federación, 1(1), 73-89. https:// revistas-colaboracion.juridicas.unam.mx/index.php/justicia-electoral/article/view/12032 